Max-Planck-Institut für demografische Forschung

Max Planck Institute for Demographic Research

Konrad-Zuse-Strasse 1 - D-18057 Rostock - GERMANY

Tel +49 (0) 3812081 - 0; Fax +49 (0) 3812081 - 202;

http://www.demogr.mpg.de

MPIDR WORKING PAPER WP 2003-033

OCTOBER 2003

\title{
A new method for correcting the under- estimation of disabled life expectancy inherent in conventional methods: Application to the oldest old in China
}

Zeng Yi (zengyi@duke.edu)

Gu Danan

Kenneth C. Land

(C) Copyright is held by the authors.

Working papers of the Max Planck Institute for Demographic Research receive only limited review.

Views or opinions expressed in working papers are attributable to the authors and do not necessarily reflect those of the Institute. 


\title{
A NEW METHOD FOR CORRECTING THE UNDERESTIMATION OF DISABLED LIFE EXPECTANCY INHERENT IN CONVENTIONAL METHODS: APPLICATION TO THE OLDEST OLD IN CHINA 1
}

\author{
Zeng Yi, Gu Danan and Kenneth C. Land ${ }^{2}$
}

\begin{abstract}
This article demonstrates that the widely used disabled life expectancies based on conventional methods are significantly underestimated due to assuming no functional status changes between age $x$ and death. We propose a new method to correct the bias and apply it to the longitudinal survey data of about 9,000 oldest old Chinese aged 80-105 collected in 1998 and 2000. In our application the age trajectories of ADL status-specific death rates and ADL state transition probabilities of the oldest old were investigated for the first time in a developing country. We have estimated the biascorrected disabled and active life expectancies of Chinese oldest old, and demonstrate patterns of large differentials associated with initial status, gender and advances in ages. Employing combined information on ADL and length of having been bedridden before dying, we analyze gender and age patterns of the extent of morbidity before dying among the oldest old and the implications of the debating hypothesis of compression of morbidity.
\end{abstract}

\section{INTRODUCTION}

\footnotetext{
${ }^{1}$ This article is based on data derived from the Chinese Longitudinal Healthy Longevity Survey, which was supported by NIA/NIH grant P01 AG 08761 awarded to Duke University and Chinese matching input towards personnel costs and some local expenses. The Max Planck Institute for Demographic Research provided support for international training.

${ }^{2}$ Zeng Yi is Research Professor of the Center for Demographic Studies and the Department of Sociology of Duke University, Professor of China Center for Economic Research at Peking University, and Distinguished Research Scholar at the Max Planck Institute for Demographic Research. Gu Danan is Research Associate at the Sanford Institute for Public Policy at Duke University. Kenneth C. Land is John Franklin Crowell Professor of Sociology and Director of the Center for Demographic Studies at Duke University. Correspondence should be sent to: Zeng Yi, Center for Demographic Studies, Duke University, Campus Drive, Box 90408, Durham, NC.
} 
At the population level, demographers have used the Sullivan method and multi-state life table models to efficiently summarize information about functional capacity in Activities of Daily Living (ADL) obtained in surveys in the form of estimates of active and disabled life expectancy. These estimates provide easily understandable indicators of the functional capacity and care-giving needs of the elderly population (Crimmins, Hayward, and Saito 1994, 1996; Crimmins, Saito, and Ingegneri 1997; Robine, Mathers, and Bucquet 1993; Rogers, Rogers, and Belanger 1990; Rogers, Rogers, and Branch 1989). The Sullivan method (Crimmins, Saito, and Ingegneri 1989; Robine et al. 1986; Wilkins and Adams 1983) is a useful approach for providing period-specific summary measures of disability status when longitudinal data on transitions between functional statuses and mortality differentials among people with different functional statuses are not available. When such longitudinal data are available, the multi-state life table method, which accounts for dynamic changes in functional statuses and the mortality differentials, is preferable (Crimmins et al. 1994, 1996; Crimmins et al.1997; Laditka and Hayward 2003; Land, Guralnik, and Blazer 1994; Manton and Land 2000a; Rogers et al. 1990; Rogers et al. 1989). A recent innovation in the calculation of healthy life expectation is microsimulation that simulates monthly health status transition probabilities and permits the calculation of the sampling errors attributable to the model's parameters (Laditka and Wolf 1998; Wolf and Laditka 1997).

Extant studies of active/disabled life expectancy based on conventional methods implicitly assume that persons who die between ages $x$ and $x+1$ (or ages $x$ and $x+n$ ) do not change their functional status between age $x$ and time of death. Such an assumption-due mainly to a lack of data about functional status before dying - causes inherent biases in the estimates of active/disabled life expectancy, with disabled life expectancy particularly significantly underestimated. The main objectives of this paper are to present a new method for correcting this bias and an application to

27708, U.S.A. Email: zengyi@duke.edu. 
data on the oldest old in China. This will be done by extending the conventional multi-state life table method for the estimation of status-based active/disabled life expectancy (i.e., active/disabled years of life remaining conditional on health status at certain ages) to include disability information before dying collected in the Chinese Longitudinal Healthy Longevity Survey (CLHLS).

Inclusion of disability information in life table analysis also has its own significance in scientific studies of aging. Based on Medicare data, Lubitz and Prihoda (1983) showed that 28 percent of all Medicare costs were incurred by the 6 percent of enrollees who died within the next 12 months. Another study found substantial increases in several measures of health care utilization with increasing proximity to death (Roos, Montgomery, and Roos 1987). If an individual experiences severe suffering for an extended period before dying, much pain and burden will be brought on the individual, family, and society. Hence, it is important to study both survivors' health and deceased elders' quality of dying.

Demographic studies of active/disabled life expectancy that make estimates conditional on health status before dying are rare due to the lack of such data. One recent study that used estimates of health status before dying is that of Manton and Land (2000a). Given a lack of data, Manton and Land estimated heath status changes before death for the deceased elderly by assuming that their probabilities of health status transitions are the same as those for survivors with the same sex, age, health status, and some other characteristics observed in the previous survey. This is better than completely ignoring the health status changes of deceased elders, but the assumption involved is only an approximation, as deceased elders' health status transitions may substantially differ from those of survivors even if they had the same conditions and characteristics in the previous interview. ${ }^{1}$

In a recent extensive literature review, George (2002) termed efforts to conceptualize the quality of dying a "young" research field, with much fewer and, consequently, less sophisticated 
studies than those for quality of life. Steinhauser and colleagues identified six primary domains of quality of dying: symptom and pain, clarity of decision-making, preparation for death, completion, contribution to others, and affirmation of the whole person (Steinhauser, Christakis, Clipp et al. 2000; Steinhauser Clipp, McNeilly et al. 2000). We will investigate the extent of morbidity before dying, one of the primary domains of quality of dying, due mainly to the lack of data on other domains.

Only a few studies had examined active/disabled life expectancy for developing countries (Chen and Jones 1989; Ham-Chande 2003; Lamb 1992, 1999), until the World Health Organization's recent active/disabled life expectancy studies based on health surveys conducted in 1999 in 19 developing countries (Mathers et al. 2003; Üstün et al. 2001). Saito, Qiao, and Jitapunkul (2003) concluded in a recent review chapter that studies of health life expectancy in Asian countries are currently relatively few. In particular, there have been relatively few studies published to date on Chinese active/disabled life expectancy. Most of those few studies used crosssectional sample survey data; none of the previous Chinese studies on active/disabled life expectancy are status-based (Grab, Dowd, and Michel 1991; Li and Tang 2002; Qiao et al. 1993; Qiao 1997; Tu and Chen 1994a, 1994b; Wang 1993; Zeng et al. 2001;Zhong, Chen, and Yao 1997). Moreover, status-based active/disabled life expectancy studies using data from nationally representative longitudinal surveys with a large enough sample size representing the oldest old subpopulation are so far not available at all for developing countries.

The projected average annual increase rate of oldest old persons aged $80+$, who most likely need help, is nearly twice as great as that of the entire elderly population aged $65+$ between 2000 and 2050 in China and elsewhere in the world (United Nations 2001). These facts indicate a significant need to investigate the active/disabled life expectancy of the oldest old, which measures the health status and care giving needs for this group. Thus, the substantive insights gained from 
this study will fill an information gap of an important topic; it is useful not only for China, but for the international scientific community as well.

\section{METHOD: An Extension of the Multi-State Life Table Method to Include Functional Status before Dying for Correcting the Significantly Underestimated Disabled Life Expectancy by the Conventional Methods}

The active and disabled life expectancies computed from multi-state life tables are average lengths of life in the active and disabled statuses that would be observed if a hypothetical cohort of elders experienced throughout their remaining life the observed age-status-specific rates of death and transition between active and disabled statuses. This is similar to the classic period life expectancy. Although the active and disabled life expectancies are neither reflections of cohort experience nor predictive of active and disabled status into the future, they do provide concise and meaningful summary measures of the current situation in the population under study.

On average, persons who have different ADL statuses at an initial age (denoted as y) are expected to have different active/disabled life expectancies and total life expectancies. The statusbased multi-state model of active/disabled life expectancy estimates such differentials for those who have different ADL statuses at initial ages (see, e.g., Manton and Land 2000a). We decompose the expected length of the remaining life span after initial ages $80,85,90,95$, and 100 into active and disabled components for those who are active or disabled at the initial age, respectively, and investigate their differentials. Our empirical estimates (later herein) are given for both the male and female oldest old, but we omit the gender dimension in all notation and equations for simplicity of presentation.

Denote ${ }_{i y} l(x)$ as the life table number of persons with ADL status $i$ at initial age $y$, and ADL status $j$ at age $x(y \leq x)$. 
$l_{j}(x)$, the life table total number of persons with ADL status $j$ at age $x$ regardless of ADL status at initial age $y$;

${ }_{1} p_{k j}(x)$, the probability of surviving and transiting from ADL status $k$ to $j$ between age $x$ and $x+1$ among those who had ADL status $k$ at age $x$;

${ }_{1} q_{i}(x)$, the probability of death between age $x$ and $x+1$ in a one-year period for those with ADL status $i$ at age $x$.

${ }_{i y} d_{j}^{(\cdot)}(x)$, the life table total number of deaths regardless of ADL status before dying between age $x$ and $x+1$ among those who had ADL status $i$ at initial age $y$ and survive with ADL status $\mathrm{j}$ at age $x,{ }_{i y} d_{j}^{(\cdot)}(x)={ }_{i y} l_{j}(x) \cdot q_{j}(x)$;

${ }_{i y} d_{j}^{(k)}(x)$, the life table number of deaths between age $x$ and $x+1$ with ADL status $k$ before dying and ADL status $i$ at initial age y and ADL status $j$ at age $x$;

$d_{j}^{(k)}(x)$, the life table total number of deaths between age $x$ and $x+1$ with ADL status $k$ before dying and ADL status $j$ at age $x$ regardless of ADL status at initial age $y$;

${ }_{n} D_{j}^{(k)}(x)$, the observed number of persons who were aged $x$ and with ADL status $j$ in the first wave, but died with ADL status $k$ before dying prior to the second wave of the survey; the left subscript $\mathrm{n}$ represents the average interval (number of years) between the first and the second waves (interviews) of the survey: approximately 2.2 years between our 1998 and 2000 waves.

We decompose ${ }_{i y} d_{j}^{(.)}(x)$ by ADL status before dying:

$$
{ }_{i y} d_{j}^{(k)}(x)={ }_{i y} d_{j}^{(.)}(x) \frac{{ }_{n} D_{j}^{(k)}(x)}{\sum_{k=1, C}{ }_{n} D_{j}^{(k)}(x)}
$$

Our decomposition of ${ }_{i y} d_{j}^{(.)}(x)$ expressed in Eq. (1) is similar to the decomposition of deaths 
by causes of deaths for elders who were active or inactive at the beginning of the two-survey observation interval by Hayward, Crimmin, and Saito (1998) in an ALE multi-state life table analysis. It is also similar to the approach employed in the multiple-decrement cause-specific mortality life table (Namboodiri and Suchindran 1987).

We denote ${ }_{i y} S_{j}^{(k)}(x)$ as the number of persons who were with ADL status $i$ at initial age $y$, ADL status $j$ at age $x$ and survive to $x+1$ with ADL status $k ;{ }_{i y} L_{j}(x)$, person-years lived in ADL status $j$ between ages $x$ and $x+1$ for those with ADL status $i$ at initial age $y$;

$$
{ }_{i y} S_{j}^{(k)}(x)={ }_{i y} l_{j}(x) \cdot p_{j k}(x)
$$

Assuming a uniform distribution of both deaths and transitions between functional statuses (i.e., assuming piecewise-linear functions for $\left.{ }_{i y} l_{j}(x)\right)$, ${ }_{i y} L_{j}(x)$ can be estimated as follows:

$$
{ }_{i y} L_{j}(x)=\left[{ }_{i y} S_{j}^{(j)}(x)+\frac{1}{2} \sum_{k=1, C}^{k \neq j}{ }_{i y} S_{j}^{(k)}(x)+\frac{1}{2} \sum_{k=1, C}^{j \neq k}{ }_{i y} S_{k}^{(j)}(x)\right]+\frac{1}{2}\left[{ }_{i y} d_{j}^{(j)}(x)+\frac{1}{2} \sum_{k=1, C}^{k \neq j}{ }_{i y} d_{j}^{(k)}(x)+\frac{1}{2} \sum_{k=1, C}^{j \neq k}{ }_{i y} d_{k}^{(j)}(x)\right]
$$

Note that the equation for computing ${ }_{i y} L_{j}(x)$ in the conventional piecewise-linear multi-state life table on active/disabled life expectancy is as follows:

$$
\begin{gathered}
{ }_{i y} L_{j}(x)=\frac{1}{2}\left[_{i y} l_{j}(x)+{ }_{i y} l_{j}(x+1)\right]={ }_{i y} l_{j}(x+1)+\frac{1}{2}\left[{ }_{i j} l_{j}(x)-{ }_{i y} l_{j}(x+1)\right] \\
=\left[{ }_{i y} l_{j}(x) p_{i j}(x)+\sum_{k \neq j} l_{i y}(x) p_{k j}(x)\right]+\frac{1}{2}\left[{ }_{i y} l_{j}(x)-{ }_{i y} l_{j}(x) p_{j i}(x)-\sum_{k \neq j} l_{k}(x) p_{k j}(x)\right] \\
={ }_{i y} S_{j}^{(j)}(x)+\frac{1}{2} \sum_{k=1, C}^{k \neq j}{ }_{i y} S_{k}^{(j)}(x)+\frac{1}{2} \sum_{k=1, C}^{k \neq j}{ }_{i y}^{(k)}(x)+\frac{1}{2}{ }_{i y} d_{j}^{(j)}(x)+\frac{1}{2} \sum_{k \neq j}{ }_{i y} d_{j}^{(k)}(x)
\end{gathered}
$$

The term $\frac{1}{2} \sum_{k \neq j}{ }_{i y} d_{j}^{(k)}(x)$ in Eq. (3) implies that those who were with ADL status $j$ at age $x$ and died between age $x$ and $x+1$ contribute on average half a year of person-years lived in status $j$. In other words, the conventional method for estimating ${ }_{i y} L_{j}(x)$ assumes that there are no ADL status changes between age $x$ and time of death for those who die between age $x$ and $x+1$. This is an unreasonable assumption, which causes bias in estimating status-based active/disabled life 
expectancy based on the conventional method, because the health status of those who die between age $x$ and $x+1$ may change between age $x$ and death, more likely becoming worse before dying.

In contrast, our new method for estimating ${ }_{i y} L_{j}(x)$ expressed in Eq. (2) uses follow-up information on observed deaths $\left({ }_{n} D_{j}^{(k)}(x)\right)$ classified by ADL status at age $x$ in the previous wave of the survey and ADL status before dying prior to the next wave. We assume a uniform distribution of changes in ADL status between ages $x$ and death among deceased persons. This method removes the unreasonable assumption imposed in the conventional method that there are no ADL status changes between age $x$ and time of death for those who die between age $x$ and $x+1$. We believe that this is an improvement in active/disabled life expectancy estimation. The bias (i.e., Eq. (3) minus Eq. (2)) in estimating ${ }_{i y} L_{j}(x)$ based on the conventional method is $\left[\frac{1}{4} \sum_{k \neq j} d_{j}^{(k)}(x)\right.$ $\left.\frac{1}{4} \sum_{k \neq j} d_{i y}^{(j)}(x)\right]$, and:

The bias in estimating ${ }_{i y} e_{j}(y)=\frac{1}{4_{i y} l_{i}(y)} \sum_{t=y}^{\omega}\left[\sum_{k \neq j}{ }_{i y} d_{j}^{(k)}(t)-\sum_{k \neq j} d_{i y}^{(j)}(t)\right]$

The bias in estimating $e_{j}(y)$ (regardless of functional status at initial age $\left.y\right)=$ $\frac{1}{4 l_{i}(y)} \sum_{t=y}^{\omega}\left[\sum_{k \neq j} d_{j}^{(k)}(t)-\sum_{k \neq j} d_{k}^{(j)}(t)\right]$

We will discuss the direction and magnitude of the bias below in the numerical application of our extended multi-state life table method for estimating active/disabled life expectancies using the Chinese data.

It is interesting to note that the classic Sullivan method applies the observed period age-specific proportions of active/disabled statuses to the number of survivors at age $x(l(x))$ of a typical mortality life table to decompose $l(x)$ into $l_{i}(x)$, where $i$ indicates active/disabled status at age $x$. 
The Sullivan method then uses the same formula (3) without the left-side subscript " "iy" (i.e. regardless of functional status at initial age $y$ ) to estimate the person-year lived in status $j$ between age $x$ and $x+n$. Consequently, the Sullivan method also implicitly assumes that there are no functional status changes between age $x$ and time of death for those who die between age $x$ and $x+n$, and thus inherently includes the bias in estimated active/disabled life expectancy. Similarly, the inherent bias based on the Sullivan method can be estimated using Eq. (5). Unfortunately, however, it is impossible to apply Eqs. (1) and (2) to correct the inherent bias in the Sullivan method, because the Sullivan method, which relies on cross-sectional data, accounts neither for dynamic changes between the active and disabled statuses, nor for the mortality differentials of the functional status. More specifically, Eqs. (1) and (2) for correcting the bias are not applicable in the Sullivan approach since ${ }_{1} q_{i}(x),{ }_{n} D_{j}^{(k)}(x)$ and ${ }_{1} p_{k j}(x)$ are not included in the Sullivan method and are not available in the cross-sectional data on which the Sullivan method is based.

Similar to the approach for decomposing the total number of deaths into cause-specific deaths in the multi-state life table of ALE analysis (Hayward, Crimmin, and Saito 1998) and in the multiple-decrement cause-specific mortality life table (Namboodiri and Suchindran 1987), we estimate ${ }_{i y} d_{j}^{(k)}(x)$ through decomposing ${ }_{i y} d_{j}^{(.)}(x)$ by morbidity status before dying (as shown in Eq. (1)), based on the observed data. Note that ${ }_{i y} l_{i}(y)=\sum_{i=y}^{\infty} \sum_{j=1}^{C} \sum_{k=1}^{C}{ }_{i y} d_{j}^{(k)}(t)$. Hence, the proportion of deaths with morbidity status $k$ before dying (i.e., extent of morbidity) after age $y$ among those with ADL status $i$ at age $y$, denoted as ${ }_{i y} G_{i}^{(k)}(y)$, is

$$
{ }_{i y} G_{i}^{(k)}(y)=\frac{\sum_{t=y}^{\omega} \sum_{j=1}^{C}{ }_{i y} d_{j}^{(k)}(t)}{{ }_{i y} l_{i}(y)}
$$


Note that Eqs (1)-(6) represent our extension of the standard model of multi-state life tables to include functional status information before dying, and are discussed intensively in this paper ${ }^{2}$. All of the other equations concerning status-based multi-state life tables construction and their theoretical assumptions (e.g., the Markovian assumption) and justifications used herein can be accessed in standard textbooks (e.g., Palloni 2001; Rogers 1975; Schoen 1988).

\section{DATA AND MEASUREMENTS}

The data used in this paper were derived from the first two waves of the Chinese Longitudinal Healthy Longevity Survey conducted in a randomly selected sample of about half of the counties and cities in 22 provinces (out of 31 provinces) in 1998 and 2000, covering about 85\% of the total population of China. All centenarians who voluntarily agreed to participate in the study in the sampled areas were interviewed. For each centenarian, one near-by octogenarian (aged 8089) and one near-by nonagenarian (aged 90-99) of pre-designated age and sex was interviewed. "Near-by" is loosely defined - it could be in the same village or on the same street, if available, or in the same town, sampled county or city. The predefined age and sex that are used to identify the approximately equal numbers of male and female nonagenarians and octogenarians at each age from 80 to 99 are randomly determined, based on the code numbers of the centenarians.

Among the 8,805 voluntary participants aged 80-105 interviewed in the baseline survey in 1998, there are 463 and 1,811 male and female centenarians aged 100-105, 1,316 and 1,719 male and female nonagenarians aged 90-99, and 1,768 and 1,728 male and female octogenarians aged $80-89$. In the second wave in 2000 , out of 8,805 original interviewees, $4,691(53.3 \%)$ survived; $3,270(37.1 \%)$ were dead; $844(9.6 \%)$ were untraceable. This is the first nation-wide longitudinal survey research project on oldest old aged $80+$ with such a large sample size ever conducted. Detailed descriptions of the study design of the Chinese longitudinal surveys on healthy longevity 
conducted in 1998 and 2000 can be found in Zeng, Vaupel, Xiao, Zhang, and Liu (2001; 2002), and thus are not repeated here.

Extensive questionnaire data collected from interviewees include ADL; physical performance; cognitive function; chronic diseases and their adverse impacts on daily life; and visual, hearing, and other kinds of health information. The data also include demographic and family household characteristics, self-reported health, self-reported life satisfaction, life style, diet, psychological characteristics, economic resources, and family support, etc.

Follow-up information about ADL active or disability, length of being bedridden, chronic disease (not usable, as to be discussed later), marital status, economic conditions, household structure etc. before dying was obtained concerning 3,270 oldest old who had been interviewed in 1998 but had died before the 2000 survey by interviewing a close family member of these deceased interviewees. Information on socioeconomic and demographic characteristics, such as marital status, family structure, and living arrangement before death, as well as whether the subject had been able to obtain adequate medical treatment when suffering from disease were also collected. As reviewed by George (2002), the use of surrogate or proxy responses from family members is appropriate in quality of dying research ${ }^{3}$.

We believe that the age reporting of the oldest old in the Chinese Healthy Longevity Survey is of acceptable quality. This conclusion is based on previous studies on age reporting of the oldest old in China (Coale and Li 1991; Wang, Zeng, Vaupel, and Jeune 1998). It is also based on the fairly similar age distributions between centenarians interviewed in our 1998 survey and centenarians in Sweden, which has the most accurate demographic data in the world (see Figure 1 in Zeng, et al. 2001). A careful evaluation (based on reliability coefficients, factor analysis, the rates of logically inconsistent answers, etc.) has been conducted (Zeng, et al. 2001; Zeng, et al. 2002). The reliability coefficients of the 10 categories of variables are reasonable (e.g., see Table 3 in Zeng, et al. 2001). 
For example, the ADL reliability coefficient is 0.88 and 0.87 in the 1998 and 2000 surveys, respectively, as compared to 0.87 in the Duke Older Americans Resources and Services Program Survey (Fillenbaum 1988) and 0.89 in the Canadian 1991-1992 elderly survey (Penning and Laurel 1994). The factor analysis demonstrates that the interviewees' answers to questions within the same category but concerning different aspects are generally consistent. The rates of logically inconsistent answers and "missing" data are reasonably low (see Appendix B in Zeng, et al. 2001).

The above-mentioned indicators lead us to believe that the data quality of the Chinese survey on healthy longevity is generally acceptable. However, we also realize that some problems exist in the data set. For example, trial analysis has shown that self-reported information about chronic disease collected from surviving interviewees and deceased interviewees' family members in our Chinese survey are not usable especially among the rural elderly, who constitute the majority of the Chinese population, because the medical conditions are so poor in rural areas that many people there have not heard of most of the names of most of the diseases listed in the questionnaire.

The elders' status of independence in daily living used in estimating the status-based active/disabled life expectancy with consideration of ADL before dying is measured by the functional statuses of eating, dressing, transferring, using the toilet, bathing, and continence ${ }^{4}$. To avoid problems of small sub-sample sizes in estimating sex-age-specific ADL status transition probabilities for the multi-state life table construction, we simply dichotomized the ADL functional capacity into "active" and "disabled". This is the same as in most of the previous studies of active/disabled life expectancy following the increment-decrement life table approach (e.g., Crimmins et al. 1997; Land et al. 1994; Rogers et al. 1989) ${ }^{6}$. If none of the six ADL activities is impaired, the elder is classified as "active"; if one or more activities are impaired, the elder is classified as "disabled". The dichotomized ADL statuses of "active" and "disabled" are used in computing dynamics of ADL statuses of both survivors and deceased elders to estimate the status- 
based active/disabled life expectancy with consideration of changes in ADL between the last interview and death, using our proposed new method expressed in formulas (1) and (2).

The extent of morbidity is approximately measured by a combination of ADL status and the number of days of being bedridden before dying. Table A1 in the Appendix presents the simple and relatively detailed frequency distributions of ADL active/disabled and days of being bedridden before dying. These and the other relevant data on the dynamics of ADL statuses of both survivors and deceased elders plus the ADL-specific mortality rates were used to estimate the proportions of deaths with different extents of morbidity before dying after age y among those who were ADL active or disabled at age y, using formulas (1), (2), and (6).

\section{FINDINGS}

\section{Underestimation of Disabled Life Expectancies Based on the Conventional Methods}

As shown mathematically in the method section, the conventional methods for estimating $_{i y} L_{j}(x)$, person-years lived in ADL status $\mathrm{j}$ between age $x$ and $x+1$, assumes that there are no ADL status changes between age $x$ and time of death for those who die between age $x$ and $x+1$. This causes bias in estimating status-based active/disabled life expectancy. Table 1 presents the estimates of such biases based on a comparison between status-based active/disabled life expectancies derived by the conventional method and by our extended method, which takes into account ADL changes between age $x$ and death. The relative biases are sizable in most cases. For example, the expected remaining years of life spent in the disabled status for males who are active at ages 80,90 , and 100 are underestimated by $12.3,8.5$, and 10.3 percent, which are statistically significant $^{7}$. Their active life expectancies are overestimated by $1.4,2.1$, and 1.4 percent (not statistically significant), respectively (see Table 1). The relative biases in the underestimation of disabled life expectancy for the female oldest old who are active at ages 80, 90, and 100 are 6.8, 
6.3, and 9.2 percent, respectively, which are statistically significant; their active life expectancies are overestimated by $1.3,2.2$, and 2.5 percent (not statistically significant).

\section{$\underline{\text { Insert Table } 1 \text { About Here }}$}

For the male oldest old who were disabled at age 85,90 , and 100, their active life expectancies were underestimated by $1.5,6.5$, and 15.4 percent (mostly statistically significant) and their disabled life expectancies were overestimated by 1.1, 2.9, and 4.5 percent (not statistically significant), respectively, using the conventional method. A similar pattern of biases was also found among the female disabled oldest old (see Table 1).

In sum, the conventional method and lack of ADL data before dying have caused the percent of remaining life in disabled status among those oldest old who are active at initial ages to be significantly underestimated (8.5-12.3\% for males and 5.8-9.2\% for females). Based on our new method and the observed data, it seems clear that among the oldest old, the lower the age, the larger the underestimation of total disabled life expectancy (regardless of ADL status at the initial ages), due to cumulative effects (see Figure 1). The underestimation of the disabled life expectancy for male oldest old is substantially larger than that for their female counterparts (see Figure 1). This is because the time spent in disabled status for those who were active at age $x$ and died between age $x$ and $x+1$ is more likely underestimated by the conventional method than that for those who were disabled at age $x$ and died in the age interval (see Eqs. (4) and (5)); and the male oldest old who died between age $x$ and $x+1$ were more likely active at age $x$ than their female counterparts.

Using the new method and extrapolated data at ages $65-79^{8}$, we also found that the underestimation of the total disabled life expectancy increases from 9.5 percent at age 80 to 12.0 percent at age 65 for males. The underestimates of the female total disabled life expectancy at ages 65,70 , and 75 are around 5.5-6.5 percent, which do not differ substantially from that at age 80 . The underestimates of total disabled life expectancy at ages 65,70 , and 75 for both males and females 
are all statistically significant at a level of $p<0.001$. Such simulated results for ages $65-79$ can be mathematically interpreted from Eq. (5), but they are premature; a more in-depth understanding will have to be based on future research when the longitudinal data including ADL status of survivors and ADL status before dying of deceased interviewees are available for the younger elderly aged $65-79$.

The underestimates of disabled life expectancy using the conventional method due to the unreasonable assumption of no functional status changes between age $x$ and death are sizable and statistically significant. The extended method and data employed in this article improve the estimates of disabled life expectancies, as compared to the conventional method, since it removes an unreasonable assumption. The biases in estimating expected years in the active status are mostly not statistically significant; biases in estimating the overall life expectancy (i.e., active and disabled life expectancy combined, see last column of Table 1) based on the conventional method are, however, negligible due to the counteracting effects of overestimates and underestimates of the active and disabled life expectancy.

\section{Age trajectories of ADL status-specific death probabilities and ADL status transition probabilities}

Single-year age and ADL status-specific death probabilities and single-year age specific ADL status transition probabilities based on the 1998-2000 longitudinal surveys data are needed for constructing the multi-state life tables to estimate the status-based active/disabled life expectancy of the oldest old. Working directly with the single-year age intervals of the original data would cause the serious problem of random fluctuations due to small sub-sample sizes at each single age for each sex. We, therefore, first estimated five-year age- and ADL-status-specific death probabilities ${ }^{9}$ and five-year age specific ADL status transition probabilities ${ }^{10}$. We then evaluated the fits of 
various models, such as the Gompertz, Weibull, Quadratic, Logistic, and Simplified Logistic models $^{11}$, to the 5 -year age specific data, following the Least Squares approach ${ }^{12}$ to model fitting and using the software Origin 7.0 (OriginLab 2002). The logistic model ${ }^{13}$ fits the data very well. It performs better than the other models we tried. The observed and the fitted curves of the death rates among active and disabled oldest old men and women aged 80-105 based on the logistic model are remarkably close to each other (see Figures $2 \mathrm{a}-2 \mathrm{~d}$ ). Note that the logistic model also fits remarkably well the overall age-specific death rates without distinguishing active and disabled statuses of the oldest old aged 80 and above for 12 European countries and Japan, all of which have high quality data (Thatcher, Kannisto, and Vaupel 1998). Zeng and Vaupel (2003) demonstrated that the logistic model (and its simplified form) describes the age trajectory of overall age-specific death rates disregarding active and disabled status among the Chinese oldest old aged 80+, based on the 1990 census data.

Using the parameters of the logistic model estimated from data on the 5-year age- and ADLstatus-specific death rates, we estimated single-year age specific death rates among active and disabled men and women ${ }^{14}$. The age trajectories of ADL-status-specific death rates show that the risk of dying among disabled oldest old men and women is about twice as high as that of the active oldest old. ADL status is clearly a strong predictor of mortality at extremely advanced ages.

\section{Insert Figures 2a-2d About Here}

The age trajectories exhibited in Figures $3 \mathrm{a}-3 \mathrm{~d}$ show that the transition probabilities of remaining active for the active oldest old decline exponentially with age, while the probability of becoming disabled increases substantially. The male and female probabilities of recovering from disabled to active status at the oldest old ages are very low and decline exponentially from slightly over 0.3 at age 80 to $0.05-0.1$ among centenarians. These provide evidence that the probability of remaining or recovering the capacity for self care of the oldest old declines quickly with advancing 
age.

\section{Insert Figures 3a-3d About Here}

\section{Gender and age differentials of status-based active/disabled life expectancies}

Several interesting observations can be drawn from the estimates of status-based active/disabled life expectancies based on our extended method that include information of ADL changes between age $x$ and death. First, the percent of remaining life spent in the active status differs tremendously between those oldest old who were active and those who were disabled at the initial ages. For example, a man who was active at ages 80, 90 and 100, would expect to spend about 90,80 , and 78 percent of his remaining life in the active status, in contrast to 67,31 , and 26 percent for a man who was disabled at ages 80,90 , and 100 . The same pattern of extremely large differences in active/disabled life expectancies between the female oldest old who were active and the female oldest old who were disabled was also found (see Table 2 and Figure 4).

\section{Insert Table 2 and Figure 4 About Here}

Second, gender differentials in active/disabled life expectancies among the Chinese oldest old who were active at the initial ages are rather large with an obvious female disadvantage; such gender differentials tend to increase with advancing age. For example, the portions of remaining life in the active status of the male oldest old who were active at ages 80,90 , and 100 were $7,8,17$ percent higher than those of their female counterparts, respectively (see Figure 4). There is, however, no clear pattern of gender differentials in active/disabled life expectancies among the Chinese oldest old who were disabled at the initial ages: the male and female curves crossover each other and the differences are mostly small (see Figure 4).

Third, the percent of active life expectancy among those male and female oldest old who were active at the initial age declines slightly from age 80 to 105 , especially after age 90 . The percent of 
active life expectancy among the oldest old men and women who were disabled at the initial age declines very quickly from age 80 to age 90 and declines moderately from age 90 to 95 . This percent remains unchanged after age 95 among males, but continues to decline substantially after age 95 among females (see Table 2 and Figure 4).

\section{Life table proportions of the extent of morbidity before dying among the oldest old who are active or disabled at initial ages}

As discussed earlier, data on ADL status before dying among the deceased oldest old were collected in the Chinese Healthy Longevity Survey and employed to improve the estimation of disabled and active life expectancy — as an easily understandable summary indicator of functional capacity. We, however, believe that ADL status alone is not sufficient for measuring the extent of morbidity before dying. Therefore, we combined data on ADL status and days of being bedridden before dying to estimate the life table proportion of the extent of morbidity before dying among the oldest old who are active or disabled at initial ages, using the formula expressed in Eq. (6).

We grouped the relatively detailed data listed in Table A1 of the Appendix into four profiles to express the extent of morbidity before dying: slight morbidity, moderate morbidity, severe morbidity, and long-term severe morbidity. Each profile was named by its main characteristics. The slight morbidity profile refers to those who were ADL active \& bedridden for $<5$ days (including not bedridden). The moderate morbidity profile refers to those who were ADL active \& bedridden for 5 days or ADL disabled \& bedridden for $<5$ days. Severe morbidity refers to those who were ADL disabled \& bedridden for 5-59 days. The long-term severe morbidity profile refers to those who were ADL disabled \& bedridden for 60 days. The cutoffs of the bedridden days in defining the four profiles are arbitrary to some extent mainly based on common sense about morbidity and suffering plus consideration for a more or less even percentage distribution across the four profiles. 
The percent distributions of the four profiles of the extent of morbidity by sex, active/disabled status at the 1998 baseline survey and age at death are presented in Table A2 in the Appendix.

As shown in Table 3 and Figure 5a and 5b, the oldest old who were active at the initial age had a substantially higher chance of experiencing a slight morbidity death and a substantially lower chance of experiencing a long-term severe death than those oldest old who were disabled at the initial age. ADL status at oldest old ages is a powerful predictor of slight morbidity or long-term severe morbidity death. In general, the male oldest old had a substantially higher percent of slight morbidity deaths and a substantially lower percent of long-term severe morbidity than their female counterparts had. The gender differentials with female disadvantages in slight morbidity death and long-term severe morbidity death are remarkable, statistically significant at almost every age regardless of ADL status at initial ages ${ }^{15}$. As compared to their male counterparts, Chinese oldest old women not only survive in a more likely disabled status, but also suffer more before dying.

Our empirical results show that the life table proportions of slight morbidity death over initial age y do not decline with the increase of age y, except for males from over age 80 to over age 85 and females from over age 90 to over age 100 (see Figure 5a). The life table proportions of longterm severe morbidity death over initial ages y are rather stable (with few fluctuations) from over age 80 to over age 100 for both males and females regardless of ADL status at initial ages (see Figure 5b). This is generally consistent with previous similar studies and provides additional evidence concerning debates on the hypothesis about compression of morbidity. We will discuss this interesting finding in the following section.

\section{$\underline{\text { Insert Table } 3 \text { and Figure 5a-5b About Here }}$}

\section{DISCUSSION}

We found that the conventional multi-state life table method and the Sullivan method implicitly assume that there are no changes in functional status from age $x$ to death if a person dies 
in the age interval $(x, x+n)$ due to a lack of data on the functional status data before dying. This unreasonable assumption causes statistically significant underestimates of disabled life expectancies and overestimates of in active life expectancy which are mostly not statistically significant. Our proposed new method plus data on ADL status before dying collected in the Chinese healthy longevity survey have resulted in higher and more accurate estimates of disabled life expectancy than what the conventional method would produce.

Previous research has indicated that the underestimation of disability is one of the major problems in research on population aging (Gill et al. 2002; Guralnik and Ferrucci 2002). Based on monthly telephone interview data, Gill et al. (2002) demonstrated that estimates of disability based on the proportions of disabled persons (i.e., the prevalence rates) at different waves with longer intervals between waves (e.g. 1-5 years) could be substantially underestimated because multiple transitions from active to disabled between the waves are not captured (Guralnik and Ferrucci 2002). Gill et al. (2002) also noted that failure to count the likely transition from active to disabled statuses before dying also markedly increases the underestimation of disability, which is consistent with our findings in this paper. Gill and colleagues proposed to substantially reduce the length of the observation intervals between interviews (which will also largely increase the costs) to reduce the underestimation of disability.

This article may be considered a significant extension of the empirical research findings of Gill et al. (2002) in three respects. First, we have developed a new method plus data on functional status changes before dying to correct the bias in estimating disabled life expectancy by the conventional methods, which unreasonably assumes no functional status changes between age $x$ and death - Gill et al. (2002) noticed the problem but did not propose a solution to correct the underestimates of disabled life expectancy. Disabled life expectancy based on data collected through monthly interviews (as Gill et al. collected) using the conventional method is also underestimated. This is 
because those elderly who are active at the beginning of month $\mathrm{x}$ and die within the month may more likely become disabled between the beginning of the month and death, but the conventional methods assume that these deceased elderly remained active until death. Second, the single-year-age-specific probabilities of transitions between the active and disabled statuses employed to construct the multistate life table in this article are based on single-year-age-specific occurrence/exposure (o/e) rates of transitions between active and disabled statuses. These o/e rates are estimated using a formula that represents the analytical relationship between the observed probability of "survival" to a status (i.e., survival to active or disabled status in two-year interval in our case) and the instantaneous rates of exits and accessions (i.e., transitions between active and disabled statuses and death in our case) proposed by Preston and Coale (1982: 225). This counting of the multiple transitions between active and disabled statuses during the single-year age interval - eliminates or minimizes at least the bias using the prevalence rates which entirely ignore the multiple events, as indicated by Gill et al. (2002). Third, Gill et al. (2002) did not present and analyze gender differentials of the underestimation of disability. Our study has found that, while the underestimation of disability is significant for both sexes, the bias for males is substantially larger than that for females, because the male oldest old who died between age $x$ and $x+1$ were more likely active at age $x$ and became disabled before dying, but the females were more likely disabled at age $x$ and remained so until death (Guralnik et al. 1991; Liao et al 2000).

Thus, as compared to the underestimated disabled life expectancy using conventional multistate life table or Sullivan methods, our extended multi-state life table method and additional data collection on $\mathrm{ADL}$ and morbidity status before dying is a useful contribution from a public health point of view. It also indicates practical needs for collecting data on health status before dying in future longitudinal surveys. It is impossible to correct the inherent underestimation of disabled life expectancy in the Sullivan method, because the Sullivan method, which is based on cross-sectional 
data, accounts neither for dynamic changes between the active and disabled statuses nor for mortality differentials by the functional status. Currently, the Sullivan method is widely applied and offers the means to gauge population health both internationally and historically, given the lack/limitations of the longitudinal data (Laditka and Hayward 2003: 231). However, the extended multi-state life table method, which takes into account the dynamics of functional status and mortality differentials and corrects the inherent underestimation of disabled life expectancy, should be used if longitudinal data on dynamics of functional status for both survivors and deceased interviewees become available.

The Chinese longitudinal follow-up survey data shows that the risk of dying among disabled oldest old men and women is about twice as high as that of the active oldest old. The age-specific transition probabilities of remaining active for the active oldest old decline exponentially with age, while the probability of becoming disabled increases substantially. The male and female probabilities of recovering from disabled to active status at the oldest old ages are very low and decline exponentially. This pattern was also observed by Rogers et al. (1990). Our analysis has shown that the percent of remaining life spent in the active status differs tremendously between those oldest old who were active and those who were disabled at the initial ages. ADL status is clearly a strong predictor of mortality, disability dynamics, and active/disabled life expectancy at advanced ages, a finding that is consistent with previous studies (Fried et al. 1998; Guralnik et al. 1991; Hayward et al 1998; Manton 1988; Manton and Land 2000b; Rogers et al 1989; Scott et al. 1997; Wolinsky et al 1993).

The gender differentials in active life expectancies among the Chinese oldest old who were active at initial ages are rather large with an obvious female disadvantage. Such gender differentials tend to increase with advancing age. There is no clear pattern of gender differentials in active/disabled life expectancies among Chinese oldest old who were disabled at initial ages. This 
result is consistent with the status-based active/disabled life expectancies estimated by Hayward and his colleagues (1998) using the U.S. Longitudinal Study on Aging and by Manton and Land (2000a) using the U.S. National Long Term Care Survey data. Both of these studies found that, while females tend to live longer than males do, the proportion of remaining life spent in active status among oldest old women is smaller than that among oldest old men.

The percent of active life expectancy among those male and female oldest old who were active at the initial age declines slightly from age 80 to 105 , especially after age 90 . The percent of active life expectancy among the oldest old men and women who were disabled at the initial age declines very quickly from age 80 to age 90 and declines moderately from age 90 to 95 . This percent remains unchanged after age 95 among males, but continues to decline substantially after age 95 among females. While our study is consistent with previous findings concerning the age trajectory of active/disabled life expectancies among elders aged 90 or younger (Hayward et al 1998, Rogers et al 1989), we extend the age range of the trajectory beyond age 100.

Based on our extended method plus the data on $\mathrm{ADL}$ and the number of bedridden days before dying collected in the CLHLS study, we found that the male oldest old had a substantially higher chance of experiencing a slight morbidity death than did their female counterparts; the male life table proportions of experiencing long-term severe morbidity are substantially lower than those of their female counterparts. The gender differentials in the extent of morbidity before dying are remarkable and statistically significant. Similarly, several previous studies (which did not follow an active/disabled life expectancy approach) found that the female elderly had a worse health status than the male elderly in the last days of life in terms of disability and cognitive function (e.g., Guralnik et al. 1991; Latwon et al. 1990; Losonczy et al. 1998; Seeman 1992). The results from our status-based active/disabled life expectancy analysis also show that interviewees' ADL status (enquired in the survey) is a powerful predictor of the extent of morbidity before dying for both 
male and female oldest old. As compared with men, women not only spend a relatively larger proportion of their remaining life in the disabled status but also more likely suffer long-term severe morbidity before dying. To our knowledge, this study is the first attempt to estimate status-based life table proportion of the extent of morbidity before dying, which reinforces and extends previous studies on active/disabled life expectancies.

The Chinese 1998 baseline healthy longevity survey data show that the prevalence of ADL disability increases dramatically from less than $16.5 \%$ at age $80-89$ to $36.9 \%$ at age $90-99$, and 63.2\% at age 100-105 (Zeng and Vaupel 2002: Table 1). Other studies also indicate that, although centenarians may delay or escape some diseases, they are on average not as healthy as octogenarians and nonagenarians (e.g., Andersen-Ranberg, Schroll, and Jeune 2001; Evert et al. 2003). The age differences in life table proportions of the extent of morbidity before dying among the oldest old are, however, not substantial. The proportion of long-term severe morbidity before dying among centenarians is not substantially different from that of octogenarians and nonagenarians for both males and females. Such results suggest that a period of morbidity before death (measured by ADL and days of being bedridden in this study) of those exceptionally longlived individuals could be compressed in a relatively short duration as compared to their largely prolonged life. Our results are consistent with some previous similar studies. For example, Guralnik et al. (1991) demonstrated that a large proportion of the total years spent in the disabled status was contributed by the years just prior to death irrespective of the age at which an older individual dies. Evert et al. (2003) find that the Escapers who have onset of a disease at 100 or higher or have not yet been diagnosed with any disease except osteroarthritis made up nearly $20 \%$ of the centenarian sample.

Our current study on the extent of morbidity before dying may support the hypothesis of morbidity compression initially proposed by Fries (Fires 1980; Fries and Crapo 1981), although no 
evidence from our study supports Fries' hypothesis about the natural limit of human life expectancy. Our study also may support the dynamic equilibrium hypothesis introduced by Manton (1982): slowing down in the pace of progression of morbidity leads to an increase in the prevalence of light and moderate (but not severe) disability as mortality falls among the oldest old. Further analysis with more data to be collected is needed to determine whether Fries' hypothesis of morbidity compression or Manton's hypothesis of dynamic equilibrium is fully supported by the Chinese healthy longevity survey study. This study may, however, reject the hypothesis of $a$ pandemic of disability which says that a decrease in the fatality rate at oldest old ages leads to a significant increase in the prevalence of morbidity (Gruenberg 1977; Kramer 1980).

Selection is another factor to potentially explain why Chinese centenarians, octogenarians and nonagenarians have similar proportions of long-term severe morbidity before dying. Very old people in China have suffered major civil wars, the Second World War, very poor living conditions and inadequate medical care. As a result, the oldest old are proportionally rarer and much more selected (although the absolute number is large due to a huge population base) in China than in Western countries. For example, there were about 5-6 centenarians per million Han Chinese compared with about 60 per million in Sweden. The result of mortality selection may be that the Chinese oldest old tend to be more robust with respect to various genetic and non-genetic characteristics (e.g., Zeng and Vaupel 2003), and thus the percent of long-term severe morbidity before dying does not increase substantially at extremely advanced ages. But this selection argument is highly debatable (Kannisto 1991). It may also be possible that it is hard for the oldest old to survive for a long time in China after the onset of a severe disease because of the poor medical facilities. Furthermore, although we believe that proxy answers to the straightforward questions on deceased elders' ADL status and bedridden days are reasonably reliable (there is no evidence to show that they are significantly flawed), the extents of morbidity measured by ADLs 
and days of being bedridden before dying are only an approximations of morbidity. Given these concerns and data limitations, it would be injudicious to draw any firm conclusions about the compression of morbidity from our available data, but the present study does provide useful information to the debate on the subject.

Our finding is also useful for understanding healthy aging: if personal health maintenance and preventive interventions are well conducted, and if positive trends in reducing health risks and promoting health behaviors are obtained, more and more people would reach their nineties or $100^{\text {th }}$ birthday and then die with a similar (or slightly longer if there is less selection in the future) lengths of morbidity as those who die at younger ages. It seems to us that healthy longevity (i.e., achieving exceptional longevity while relatively compressing morbidity) is not impossible (Hubert et al. 2002). So, it is important to draw more attentions to studies not only of the determinants of healthy survival but also on what factors may contribute to slight morbidity or long-term severe morbidity before dying at oldest old ages.

One of the unique aspects of this study is that we have ADL and mortality follow-up data including proxy reports on morbidity before dying collected from the largest survey of the oldest old (2,274 centenarians, 3,035 nonagenarians, and 3,496 octogenarians) ever-conduced. The large sample size has enabled us to conduct relatively detailed analyses on status-based active/disabled life expectancy and the extent of morbidity before dying at oldest old ages above age 80 including extremely advanced ages over age 95 and 100 with sufficient sub-sample sizes. Few previous studies provide active/disabled life expectancies beyond age 100 based on regression estimation due to insufficient sub-sample size of centenarians (e.g., Manton 1997; Manton and Land 2000a, 2000b).

In her extensive literature review article, George (2002) found no evidence of attempts to randomly sample populations of interest in previous end of life research. Instead, investigators 
appeared to select a place for subject recruitment (e.g., hospice settings, palliative care units) and then simply enroll the available patients. We use relatively detailed data on health status before dying from a sample of nearly 9,000 oldest old in a randomly selected half of the counties and cities in 22 provinces consisting of $85 \%$ of China's total population. This study has clear merit in this regard since it does not rely on a single health care setting, as is the case for most of the previous end of life research.

In sum, this article demonstrates that widely existing estimates of disabled life expectancy based on either conventional multi-state life table approaches or the Sullivan method (both of which lack of ADL data before dying) are significantly underestimated; we propose a new method to correct this sizable bias. This study also improves knowledge about independence versus dependence of life and the extent of morbidity before dying at the oldest old ages in general, and, in particular, among the Chinese oldest old, about whom little demographic research has been published to date.

Our present study, however, also has limitations. First, we use a simplistic presentation of the dichotomous variables "active" and "disabled" for men and women, without detailed classifications in terms of the degree of disability, rural-urban residency, and education, etc. This limitation is due to sub-sample size problems in demographically estimating age-specific multi-dimensional ADL status transition probabilities that occur if more categories of disability and covariates are included in the multi-state life table model. Such a limitation can be largely eliminated if the static Sullivan method is adopted, but there is a tradeoff here: the Sullivan approach cannot account for dynamic changes in functional statuses and the mortality differentials for survivors and the deceased. Second, as explained in the data and measurement section, self-reported (or proxy-reported) information about chronic disease of either survivors or deceased interviewees in our demographic CLHLS survey are not usable because many Chinese oldest old even have not heard of most listed 
names of the diseases. The extent of morbidity is, therefore, measured by a combination of ADL and days of being bedridden before dying. This is a reasonable approximation, but more accurate data on the extent of morbidity including chronic disease before dying needs to be collected in the future surveys with qualified medical doctors' involvements plus medical records, perhaps in the city sub-sample ${ }^{16}$. Third, we could not offer causal explanations of the findings due to limits in the scope of the paper, methods and data employed for the analysis. Further in-depth investigations following multivariate statistical modeling approaches are necessary to develop causal explanations. Fourth, despite its uniquely large sample size among oldest old studies, the longitudinal data of two assessments with two-year observation period (1998-2000) used in this study are not sufficient to yield firm conclusions with strong statistical power on trends of disability, morbidity, and healthy longevity. For example, our findings and discussions concerning the debates on the hypothesis about compression of morbidity are preliminary. Mainly based on a 1994 workshop report prepared by the U.S. National Research Council, Freedman, Martin, and Schoeni (2002: 3138) stated in a review article on recent trends in disability that two criteria for a "good" longitudinal survey study measuring the trends of disability is a time-frame spanning at least 8 years and at least 5 assessments. Thus, we will need to use new data from additional waves with longer observation periods (hopefully to be collected in the near future through continuing our ongoing CLHLS study) to address the fundamental question of whether the recent mortality decline has been accompanied by a compression or expansion of the period of disability and morbidity (Fries 1980; Gruenberg 1977; Manton 1982). 


\section{Appendix}

Table A1. Frequency distribution of ADL active and extent of disability before dying

\begin{tabular}{|c|c|c|c|c|c|c|c|c|c|c|c|c|c|c|c|c|c|c|}
\hline \multirow[b]{2}{*}{ Age at death } & \multicolumn{6}{|c|}{ ADL active at 1998 survey } & \multicolumn{6}{|c|}{ ADL disabled at 1998 survey } & \multicolumn{6}{|c|}{ Total } \\
\hline & $\begin{array}{l}80- \\
84\end{array}$ & $\begin{array}{l}85- \\
89\end{array}$ & $90-94$ & $\begin{array}{c}95- \\
99\end{array}$ & $\begin{array}{l}100- \\
105\end{array}$ & $\begin{array}{c}\text { Tota } \\
1\end{array}$ & $\begin{array}{c}80- \\
84\end{array}$ & $\begin{array}{c}85- \\
89\end{array}$ & $\begin{array}{c}90- \\
94\end{array}$ & $\begin{array}{c}95- \\
99\end{array}$ & $\begin{array}{l}100- \\
105\end{array}$ & Total & $\begin{array}{l}80- \\
84\end{array}$ & $\begin{array}{c}85- \\
89\end{array}$ & $\begin{array}{c}90- \\
94\end{array}$ & $\begin{array}{c}95- \\
99\end{array}$ & $\begin{array}{c}100- \\
105\end{array}$ & Total \\
\hline \multicolumn{19}{|l|}{ Males } \\
\hline$\%$ of $\mathrm{ADL}$ active $\&$ not bedridden & 45.54 & 23.45 & 28.34 & 29.61 & 30.43 & 30.43 & 25.71 & 16.36 & 30.19 & 21.54 & 18.10 & 21.57 & 40.44 & 21.50 & 29.01 & 25.89 & 22.32 & 26.54 \\
\hline$\%$ of ADL active \& bedridden $<5$ days & 8.91 & 8.28 & 4.28 & 7.89 & 4.35 & 6.57 & 2.86 & 0.00 & 2.83 & 4.62 & 4.98 & 3.84 & 7.35 & 6.00 & 3.75 & 6.38 & 4.76 & 5.37 \\
\hline$\%$ of $\mathrm{ADL}$ active $\&$ bedridden $>=5$ days & 7.92 & 12.41 & 16.04 & 15.79 & 14.78 & 13.86 & 11.43 & 9.09 & 12.26 & 9.23 & 10.86 & 10.60 & 8.82 & 11.50 & 14.68 & 12.77 & 12.20 & 12.43 \\
\hline$\%$ of $\mathrm{ADL}$ disabled, bedridden $<5$ days & 6.93 & 11.03 & 14.97 & 9.21 & 17.39 & 12.14 & 14.29 & 10.91 & 15.09 & 17.69 & 19.00 & 16.82 & 8.82 & 11.00 & 15.02 & 13.12 & 18.45 & 14.19 \\
\hline $\begin{array}{l}\% \text { of } \mathrm{ADL} \text { disabled, bedridden 5-29 } \\
\text { days }\end{array}$ & 14.85 & 14.48 & 15.51 & 15.13 & 13.04 & 14.71 & 11.43 & 20.00 & 18.87 & 16.92 & 16.29 & 17.00 & 13.97 & 16.00 & 16.72 & 15.96 & 15.18 & 15.72 \\
\hline $\begin{array}{l}\% \text { of } \mathrm{ADL} \text { disabled, bedridden } 30-59 \\
\text { days }\end{array}$ & 7.92 & 9.66 & 9.09 & 5.26 & 7.83 & 8.00 & 8.57 & 7.27 & 3.77 & 8.46 & 11.76 & 8.78 & 8.09 & 9.00 & 7.17 & 6.74 & 10.42 & 8.34 \\
\hline $\begin{array}{l}\% \text { of ADL disabled, bedridden } 60-119 \\
\text { days } \\
\% \text { of ADL disabled, bedridden } 120-179\end{array}$ & 1.98 & 11.03 & 4.81 & 9.87 & 6.96 & 7.14 & 17.14 & 7.27 & 4.72 & 8.46 & 8.14 & 8.04 & 5.88 & 10.00 & 4.78 & 9.22 & 7.74 & 7.54 \\
\hline$\%$ of ADL disabled, bedridden $>=180$ & 1.98 & 3.45 & 1.07 & 2.63 & 1.74 & 2.14 & 2.86 & 3.64 & 1.89 & 3.85 & 1.36 & 2.38 & 2.21 & 3.50 & 1.37 & 3.19 & 1.49 & 2.25 \\
\hline $\begin{array}{l}\text { days } \\
\text { Females }\end{array}$ & 3.96 & 6.21 & 5.88 & 4.61 & 3.48 & 5.00 & 5.71 & 25.45 & 10.38 & 9.23 & 9.50 & 10.97 & 4.41 & 11.50 & 7.51 & 6.74 & 7.44 & 7.62 \\
\hline$\%$ of $\mathrm{ADL}$ active $\&$ not bedridden & 28.57 & 21.43 & 29.86 & 19.48 & 20.31 & 22.73 & 13.04 & 16.36 & 14.96 & 13.16 & 10.53 & 11.72 & 24.73 & 19.76 & 22.88 & 15.99 & 13.31 & 16.11 \\
\hline$\%$ of ADL active \& bedridden $<5$ days & 4.29 & 3.57 & 4.86 & 5.84 & 7.38 & 5.84 & 0.00 & 1.82 & 5.51 & 2.11 & 1.84 & 2.23 & 3.23 & 2.99 & 5.17 & 3.78 & 3.42 & 3.67 \\
\hline$\%$ of $\mathrm{ADL}$ active $\&$ bedridden $>=5$ days & 11.43 & 19.64 & 9.03 & 16.23 & 12.92 & 13.66 & 8.70 & 7.27 & 7.87 & 7.89 & 9.42 & 8.91 & 10.75 & 15.57 & 8.49 & 11.63 & 10.42 & 10.81 \\
\hline$\%$ of ADL disabled, bedridden $<5$ days & 8.57 & 13.39 & 9.72 & 12.34 & 12.31 & 11.68 & 26.09 & 9.09 & 12.60 & 18.42 & 19.71 & 18.40 & 12.90 & 11.98 & 11.07 & 15.70 & 17.60 & 15.72 \\
\hline $\begin{array}{l}\% \text { of ADL disabled, bedridden } 5-29 \\
\text { days } \\
\% \text { of ADL disabled, bedridden } 30-59\end{array}$ & 11.43 & 17.86 & 22.22 & 13.64 & 15.08 & 16.15 & 8.70 & 20.00 & 14.96 & 17.37 & 16.28 & 16.34 & 10.75 & 18.56 & 18.82 & 15.70 & 15.94 & 16.26 \\
\hline $\begin{array}{l}\text { days } \\
\% \text { of ADL disabled, bedridden } 60-119\end{array}$ & 12.86 & 7.14 & 9.72 & 10.39 & 12.00 & 10.68 & 4.35 & 9.09 & 12.60 & 9.47 & 8.81 & 9.24 & 10.75 & 7.78 & 11.07 & 9.88 & 9.72 & 9.82 \\
\hline days & 11.43 & 10.71 & 5.56 & 8.44 & 7.08 & 7.95 & 17.39 & 5.45 & 5.51 & 8.42 & 9.06 & 8.58 & 12.90 & 8.98 & 5.54 & 8.43 & 8.49 & 8.33 \\
\hline $\begin{array}{l}\text { days } \\
\% \text { of } \mathrm{ADL} \text { disabled, bedridden }>=180\end{array}$ & 0.00 & 0.89 & 2.08 & 3.25 & 2.15 & 1.99 & 4.35 & 5.45 & 4.72 & 2.63 & 4.04 & 3.96 & 1.08 & 2.40 & 3.32 & 2.91 & 3.50 & 3.17 \\
\hline days & 11.43 & 5.36 & 6.94 & 10.39 & 10.77 & 9.32 & 17.39 & 25.45 & 21.26 & 20.53 & 20.32 & 20.63 & 12.90 & 11.98 & 13.65 & 15.99 & 17.60 & 16.11 \\
\hline
\end{tabular}


Table A2. Frequency distribution of the four profiles of the extent of morbidity before dying

\begin{tabular}{|c|c|c|c|c|c|c|c|c|c|c|c|c|c|c|c|c|c|c|}
\hline \multirow[b]{2}{*}{ Age at death } & \multicolumn{6}{|c|}{ ADL active at 1998 survey } & \multicolumn{6}{|c|}{ ADL disabled at 1998 survey } & \multicolumn{6}{|c|}{ Total } \\
\hline & $\begin{array}{l}80- \\
84\end{array}$ & $\begin{array}{l}85- \\
89\end{array}$ & $\begin{array}{l}90- \\
94 \\
\end{array}$ & $\begin{array}{l}95- \\
99\end{array}$ & $\begin{array}{l}100- \\
105\end{array}$ & Total & $80-84$ & $85-89$ & $90-94$ & $95-99$ & $100-105$ & Total & $80-84$ & $85-89$ & $90-94$ & $95-99$ & $100-105$ & Total \\
\hline Males & & & & & & & & & & & & & & & & & & \\
\hline Slight & 54.4 & 31.7 & 32.6 & 37.5 & & & & & & & & & & & & & & \\
\hline morbidity & 6 & 2 & 2 & 0 & 34.78 & 37.00 & 28.57 & 16.36 & 33.02 & 26.15 & 23.08 & 25.41 & 47.79 & 27.50 & 32.76 & 32.27 & 27.08 & 31.92 \\
\hline Moderate & 14.8 & 23.4 & 31.0 & 25.0 & & & & & & & & & & & & & & \\
\hline morbidity & 5 & 5 & 2 & 0 & 32.17 & 26.00 & 25.71 & 20.00 & 27.36 & 26.92 & 29.86 & 27.42 & 17.65 & 22.50 & 29.69 & 25.89 & 30.65 & 26.62 \\
\hline Severe & 22.7 & 24.1 & 24.6 & 20.3 & & & & & & & & & & & & & & \\
\hline morbidity & 7 & 4 & 0 & 9 & 20.87 & 22.71 & 20.00 & 27.27 & 22.64 & 25.38 & 28.05 & 25.78 & 22.06 & 25.00 & 23.89 & 22.70 & 25.60 & 24.06 \\
\hline $\begin{array}{l}\text { Long-term } \\
\text { severe }\end{array}$ & & 20.6 & 11.7 & 17.1 & & & & & & & & & & & & & & \\
\hline morbidity & 7.92 & 9 & 6 & 1 & 12.17 & 14.29 & 25.71 & 36.36 & 16.98 & 21.54 & 19.00 & 21.39 & 12.50 & 25.00 & 13.65 & 19.15 & 16.67 & 17.40 \\
\hline Females & & & & & & & & & & & & & & & & & & \\
\hline Slight & 32.8 & 25.0 & 34.7 & 25.3 & & & & & & & & & & & & & & \\
\hline morbidity & 6 & 0 & 2 & 2 & 27.69 & 28.57 & 13.04 & 18.18 & 20.47 & 15.26 & 12.36 & 13.94 & 27.96 & 22.75 & 28.04 & 19.77 & 16.73 & 19.78 \\
\hline Moderate & 20.0 & 33.0 & 18.7 & 28.5 & & & & & & & & & & & & & & \\
\hline morbidity & 0 & 4 & 5 & 7 & 25.23 & 25.34 & 34.78 & 16.36 & 20.47 & 26.32 & 29.13 & 27.31 & 23.66 & 27.54 & 19.56 & 27.33 & 28.02 & 26.52 \\
\hline Severe & 24.2 & 25.0 & 31.9 & 24.0 & & & & & & & & & & & & & & \\
\hline morbidity & 9 & 0 & 4 & 3 & 27.08 & 26.83 & 13.04 & 29.09 & 27.56 & 26.84 & 25.09 & 25.58 & 21.51 & 26.35 & 29.89 & 25.58 & 25.66 & 26.08 \\
\hline $\begin{array}{l}\text { Long-term } \\
\text { severe }\end{array}$ & 22.8 & 16.9 & 14.5 & 22.0 & & & & & & & & & & & & & & \\
\hline morbidity & 6 & 6 & 8 & 8 & 20.00 & 19.25 & 39.13 & 36.36 & 31.50 & 31.58 & 33.41 & 33.17 & 26.88 & 23.35 & 22.51 & 27.33 & 29.60 & 27.62 \\
\hline
\end{tabular}




\section{ENDNOTES}

${ }^{1}$ Manton and Land (2000a:259, footnote 4) are further investigating linkages to, and the utilization of, Medicare service use data in the prior survey interval among both survivors and deceased elders. This is expected to more accurately describe the dynamics of health status changes.

2 Eqs. (1), (2), (4) and (6) are designed for estimating the status-based active/disabled life expectancies with consideration of functional status changes before dying, which are research topics of this article; they are also applicable in estimating active/disabled life expectancies regardless of functional status at initial age $y$, and in that case the left-side subscript "iy" should be deleted.

${ }^{3}$ We must rely on proxy reports for deceased persons because most Chinese old persons do not have detailed and reliable medical records. Prior studies showed that proxy reports for surviving elderly have a manageable bias (e.g., Magaziner et al. 1988; Parker et al. 1996). One of the causes of biases in proxy reports for surviving elderly is that the proxy may worry about the possibility of upsetting the elderly if he or she reports the elder's severe disability or certain types of disability (e.g., incontinence). There is usually no such worry in proxy reports for the deceased elderly. On the other hand, interviews conducted with a proxy of the deceased elder were conducted some months (ranging from 1 to 28 months in the Chinese follow-up survey) after the elder's death, and thus recall errors may occur. Although the available data do not allow us to evaluate proxy report errors for the deceased elders, we expect that the bias exists but may not be substantially larger than 
the bias of proxy reports for surviving elderly.

4 The ADL questions are based on the international standard of Katz' ADL index (Katz et al. 1963) adopted to the Chinese cultural/social context and carefully tested by pilot studies/interviews. Six questions about ADL functional statuses (can do it, can do it but need assistance, or cannot do it) were addressed to the oldest old or a close family member if the elder was not able to answer. "Eating" refers to feeding oneself. "Dressing" refers to getting clothes and getting dressed, including tying shoes. "Transferring" refers to getting in and out of bed as well as in and out of a chair. "Using the toilet" refers to going to the toilet and cleaning afterward. "Bathing" refers to a sponge bath, shower, tub bath, or washing the body with a wet towel. "Continence" refers to control of urination and bowel movement.

${ }^{5}$ Similarly, due to sample size problems, we do not distinguish rural and urban residence in our multi-state life table analysis in this paper, while we compute the life table for males and females separately. The rural-urban differential in active versus disabled life expectancy among the Chinese oldest old was estimated by the 1998 baseline survey data and the Sullivan method, which does not need age specific ADL status transition probabilities and is thus not subjected to sample size problems (Zeng et al. 2001).

${ }^{6}$ We did not use hazards models or other kinds of regression models to estimate the age-sexspecific transition probabilities among multiple (more than two) ADL statuses for two main reasons. First, the estimate of the coefficient of the age covariate in the regression model may not represent accurately the age trajectory, unless the age trajectory follows precisely linear or loglinear or another kind of analytical distribution, which is unlikely true. Secondly, the approach using regression models to estimate the age-specific ADL status transition probabilities presume that all sources of individual-level variations are explained by the covariates which enter the regressions. This specification is almost surely not true empirically, especially for extended periods 
of more than one year (Land et al. 1994: 304).

7 Molla, Wagener, and Madans (2001) show how differences in estimates of Healthy Life Expectancy (HLE) between two subgroups can be tested for statistical significance by application of the conventional statistical method used for testing difference between two means. The estimated HLE is a mean of random variable assumed to be independent each other and with normal distribution (Jagger, Hauet, and Brouard 1997). Hence, a z-score test can be constructed using the estimated HLE's of the two subgroups (The z-score is a standard normal variable estimated by transforming a non-standard normal variable). Based on the z-score test and the relevant procedures for calculating the standard errors used by Chiang (1960) and Keyfitz (1968), Molla et al. (2001) conducted statistical tests for difference of HLE between American white males and females. Using the basic method of Molla et al. (2001) with some extension, we tested statistically the difference between the active and disabled life expectancies calculated by our method including ADL status before dying and those calculated by the conventional method assuming no changes in ADL from age $x$ to death if a person dies in the age interval $(x, x+n)$. The extension is necessary because our study on status-based active/disabled life expectancy differs from the study by Molla et al. (2001) in which healthy life expectancies were not conditional on health status at initial ages. The procedures of the statistical test based on the method of Molla et al. (2001) with some extension are not presented in our paper due to space limitation but are available upon request.

${ }^{8}$ In order to explore the underestimation of disabled life expectancy below age 80 using the conventional method, which assumes no changes in functional status between age $x$ and death, we extrapolated ${ }_{1} p_{k j}(x),{ }_{1} q_{i}(x), \frac{{ }_{n} D_{j}^{(k)}(x)}{\sum_{k=1, C}{ }_{n} D_{j}^{(k)}(x)}$ to ages 65-79 through model fitting plus some expert opinion estimates, based on the corresponding observed data at ages 80-105. We then extended our 
status-based multi-state life table from ages 80-105 using observed data to younger ages 65-79 based on extrapolated data.

${ }^{9}$ We compare the five-year age specific death rates (without ADL specification) estimated from the Chinese 1998-2000 Longitudinal Healthy Longevity Survey data to those death rates at oldest old ages derived from the 2000 census (mortality data within 12 months prior to the census standard time were collected). We found that Chinese Healthy Longevity Survey death rates at ages 90 and over are fairly accurate, but the death rates at ages $80-89$ were somewhat underestimated (-9.4\% and $-8.7 \%$ at ages $80-84$ and $85-89$ for males; $-13.1 \%$ and $-6.1 \%$ at ages $80-84$ and $85-89$ for females). We, therefore, adjusted the survey death rates at ages $80-89$ based on the 2000 census data of the 22 provinces.

10 The demographic procedures and formulas for estimating the age and ADL status specific death probabilities and age specific ADL status transition probabilities based on the longitudinal survey data are not presented in this paper due to space limitation, but are available upon request.

${ }^{11}$ See Thatcher, Kannisto and Vaupel (1998: 14-18) for a detailed mathematical description and discussions of these models.

12 The Least Square estimation procedure was also employed in some other studies to fit a model to the observed age-specific data (e.g. Finch and Pike 1996; Hime, Preston, and Condran 1994; Lauderdale and Kestenbaum 2002; Muhidin 2002).

${ }^{13}$ In the logistic model, the function of the hazard rate $\mu(\mathrm{x})$ is defined as $\mu(\mathrm{x})=\mathrm{c}+\frac{\mathrm{a}^{\mathrm{bx}}}{1+\alpha^{b x}}($ Thatcher, Kannisto, and Vaupel 1998: 15).

${ }^{14}$ The approach of using the parameters of a model estimated based on the 5-year age-specific data and then estimating the single-year age-specific rates was also employed in some other studies (e.g. Muhidin 2002 ;Pollard 1989). 
${ }^{15}$ The statistical test procedure is based on the method of Molla et al. (2001) with some extension; see endnote 7 for more details.

${ }^{16}$ It would be impossible to do this in rural China not only because it costs too much to send qualified doctors to remote villages to conduct home-interviews/diagnoses but also because there are no medical records available in almost all rural areas.

\section{REFERENCES}

Andersen-Ranberg, K., Vasegard, L., and Jeune, B. (2001). Dementia is not inevitable: A population-based study of Danish centenarians. Journal of Gerontology: Psychological Sciences, 56B, P152-P159.

Chen, A.J., and Jones, G. (1989). Aging in ASEAN: Its socioeconomic consequences. Singapore: Institute of Southeast Asian Studies.

Chiang, C.L. (1960). A stochastic study of the life table and its application: II. Sample variance of the observed expectation of life and other biometric functions. Human Biology 32, 221-238.

Clark, D.O.; Stump, T.E.; and Hui, S.L. (1998). Predictors of morbidity and basic ADL difficult among adults aged 70 years and older. Journal of Aging and Health. 10(4), 422-440,

Coale, A.J. and Li, S.M. (1991). The effect of age misreporting in China on the calculation of mortality rates at very high ages. Demography, 28 (2), 293-301.

Crimmins, E.M., Hayward, M.D., and Saito, Y. (1994). Changing mortality and morbidity rates and the health status and life expectancy of the older population. Demography, 31 (1),159-175.

Crimmins, E.M., Hayward, M.D., and Saito, Y. (1996). Differentials in active life expectancy in the older population of the United States. Journal of Gerontology: Social Sciences, 51B(3), S111-S120.

Crimmins, E.M., Saito, Y., and Ingegneri, D. (1989). Changing in life expectancy and disabilityfree life expectancy in the United States. Population and Development Review, 15(2), 235-267.

Crimmins, E.M, Saito, Y., and Ingegneri, D. (1997). Trends in disability-free life expectancy in the United States, 1970-90. Population and Development Review, 23 (3), 555-572.

Evert, J., Lawler, E., Bogan, H, and Perls, T. (2003). Morbidity profiles of centenarians: Survivors, delayers, and escapers. Journal of Gerontology: Medical Sciences, 58(A), 232-237.

Fillenbaum, G. G. (1988). Multidimensional functional assessment of older adults: The Duke Older Americans Resources and Services Procedures. Hillsdale, NJ: Lawrence Erlbaum.

Finch,C.E., and Pike, M.C. (1996). Maximum life span predictions from the Gompertz mortality model. The Journals of Gerontology, 51A(3), B183-B194.

Freedman, V.A., Martin, L.G., and Schoeni, R.F. (2002). Recent trends in disability and functioning among older adults in the United States: A systematic review. Journal of the American Medical Association, 288, 3137-3146.

Fries, J.F. (1980). Aging, natural death, and the compression of morbidity. New England Journal of Medicine, 303, 130-135.

Fries, J.F. and Crapo, L.M. (1981). Vitality and aging. San Francisco: WH Freeman and Company. 
Fried, L.P., Kronmal, R.A., Newman, A.B. et al. (1998). Risk factors for 5-year mortality in older adults: The Cardiovascular Health Study. Journal of the American Medical Association, 279, 585-592.

Gill, T. M., Hardy, S.E., and Williams, C. (2002). Underestimation of disability in communityliving older persons. Journal of the American Geriatrics Society, 50, 1492-1497.

George, L.K. (2002). Research design in end of life research: State of the science. The Gerontologist, 42, 86-98.

Grab, B., Dowd, J.E., and Michel, J-P. (1991). Estimate of disability-free life expectancy in China. Paper presented at the $4^{\text {th }}$ meeting of REVES, Noordwijkerhout, Netherlands.

Gruenberg, E.M. (1977). The failures of success. Milbank Memorial Fund Quarterly/Health and Society, 55, 3-24.

Guralnik, J.M., and Ferrucci, L. (2002). Underestimation of disability occurrence in epidemiological studies of older people: Is research on disability still alive? Journal of the American Geriatrics Society, 50, 1599-1601.

Guralnik, J. M.,LaCroix, A.,Z.,Branch, L., Kasl, S., and Wallace, R.(1991). Morbidity and disability in older persons in the years prior to death. American Journal of Public Health,81,443-447.

Ham-Chande, R. (2003). Ageing and health expectancies in urban Latin America. . In J-M., Robine, C. Jagger, C.D. Mathers, E.M. Crimmins, and R.M.Suzman (eds.). Determining health expectancies, Pp318-333. John Wiley and Sons Ltd: England.

Hayward, M., Crimmins, E.M., and Saito, Y. (1998). Cause of death and active life expectancy in the older population of the United States. Journal of Aging and Health, 10(2), 192-213.

Himes, C.L., Preston, S.H., and Condran, G.A. (1994). A relational model of mortality at older ages in low mortality countries. Population Studies, 48, 269-291.

Hubert, H.B., Bloch, D.A., Oehlert, J.W., and Fries, J. (2002). Lifestyle habits and compression of morbidity. Journal of Gerontology: Medical Sciences, 57A (6), M347-M351.

Jagger, C., Hauetm E., and Brouard, N. (1997). Health expectancy calculation by the Sullivan method: A practical guide. European concerted action on the harmonization of health expectancy calculations in Europe (EURO-REVES). Institute National d'Etudes demographiques, Paris.

Kannisto, V. (1991). Frailty and survival. Genus, 47 (3-4), 101-118.

Katz, S., Ford, A.B., Moskowitz, R.W., Jack, B.A., and Jaffe, M.W. (1963). Studies of illness in the aged. Journal of the American Medical Association, 185,94-99.

Keyfitz, N. (1968). Introduction to the mathematics of population with revisions. Cambridge, MA: Addison Wesley.

Kramer, M. (1980). The rising pandemic of mental disorders and associated chronic diseases and disabilities. Acta Psychiatrica Scandinavica 62 (Suppl. 285), 282-297.

Laditka, S.B., and Hayward, M.D. (2003). The Evolution of demographic methods to calculate health expectancies. In J-M., Robine, C. Jagger, C.D. Mathers, E.M. Crimmins, and R.M.Suzman (eds.). Determining health expectancies, Pp221-234. John Wiley and Sons Ltd: England.

Laditka, S. B., and Wolf, D.A. (1998). New method for analyzing active life expectancy. Journal of Aging and Health, 10(2). 214-241.

Lamb, V.L. (1992). A cross-national study of disability among the elderly in less developed countries, dissertation. Duke, University.

Lamb V. L. (1999). Active life expectancy of the elderly in selected Asian countries. Nihon University, Population Research Institute Research Paper Series No.69. 
Land, K. C., Guralnik, J. M., and Blazer, D. G. (1994). Estimating increment-decrement life tables with multiple covariates from panel data: The case of active life expectancy. Demography, 31, 297-319.

Lauderdale, D.S., and Kestenbaum, B. (2002). Mortality rate of elderly Asian American populations based on Medicare and social security data. Demography, 39 (3), 529-540.

Lawton, M.P., Moss, M., and Glicksman, A. (1990). The quality of the last year of life of older persons. The Milbank quarterly, 68 (1), 1-28.

Li, Q., and Tang, Z. (2002). Application of multi-state life table model in research on health of elderly population. Journal of Chinese Population Science. No. 6, 2002.

Liao, Y., McGee, D.I., Cao, G. et al. (2000). Quality of the last year of life of older adults: 1986vs 1993. Journal of the American Medical Association, 283, 512-1-518.

Losonczy, K.G., White, L.R., and Brock, D.B. (1998). Prevalence and correlates of dementia: Survey of the last days of life. Public Health Reports, 113, 273-280.

Lubitz, J., and Prihoda, R. (1983). The use and costs of Medicare services in the last two years of life. Health Care Financing Review, 5, 117-131.

Magaziner, J., Simonsick, E.M., Kasher, T.M., and Hebel, J.R. (1988). Patient-proxy response comparability on measures of patient health and functional status. Journal of Clinical Epidemiology, 41, 1065-1074.

Manton, K.G. (1982). Changing concepts of morbidity and mortality in the elderly population. Milbank Memorial Fund Quarterly/Health and Society, 60, 183-244.

Manton, K.G. (1988). A longitudinal study of functional change and mortality in the United States. Journal of Gerontology, 43.(suppl 5), S153-S161.

Manton, K.G. (1997). Demographic trends among the aging female population. Journal of the American Medical Women's Association, 52(3), 99-105.

Manton, K.G., and Land, K. C. (2000a). Active life expectancy estimates for the U.S. elderly population: a multidimensional continuous-mixture model of functional change applied to completed cohorts, 1982-1996. Demography, 37(3), 253-265.

Manton, K.G., and Land, K. C. (2000b). Multidimensional disability/mortality trajectories at ages 65 and over: The impact of state dependence. Social Indicators Research, 51, 193-221.

Mathers, C.D., Murray, C. J-L., Lopez, A.D., Salomon, J.A., and Sadana, Ritu. (2003). Global patterns of health expectancy in the year 2000. In J-M., Robine, C. Jagger, C.D. Mathers, E.M. Crimmins, and R.M.Suzman (eds.). Determining health expectancies, Pp221-234. John Wiley and Sons Ltd: England.

Molla, M.T., Wagener, D.K., and Madans, J.H. (2001). Summary measures of population health: Methods for calculating healthy life expectancy. Department of Health and Human Services, Center for Disease, Control and Prevention. Also available at: http://www.cdc.gov/nchs/data /statnt/ statnt21.pdf

Muhidin, S. (2002). The population of Indonesia-regional demographic scenarios using a multiregional method and multiple data sources. Amsterdam: Rozenberg Publishers.

Namboodiri, N.K., and Suchindran, C.M. (1987), Life table techniques and their applications. Academic Press, Orlando, Florida.

OriginLab. (2002). Origin Version 7. Original Lab Corporation. http://www.originLab.com.

Palloni, A. (2001) Increment-Decrement Life Tables. In: Preston S., P. Heuveline, and M. Guillot Demography: Measuring and Modeling Population Processes, Oxford: Blackwell.

Parker, M.G., Thorslund, M., Lundberg, O., and Kareholt, I. (1996). Predictors of physical function among the oldest old: a comparison of three outcome variables in a 24-year follow-up. Journal of Aging and Health, 8 (3),444-460. 
Penning, M.J., and Laurel, A.S. (1994). Gender difference in disability, assistance and subjective well-being in later life. Journal of Gerontology: Social Science, 49,S202-S208.

Pollard, J.H. (1989). On the derivation of a full life table from mortality data recorded in five-year age groups, Mathematical Population Studies, 2(1),1-14.

Preston, S.H., and Coale, A.J. (1982). Age structure, growth, attrition, and accession: A new synthesis. Population Index, 48, 217-259.

Qiao, X.C. (1997). Healthy expectancy of China. Paper presented at the Tenth Meeting of REVES, Tokyo, Japan.

Qiao, Z.-K., Wilkins, R., Yang, M., Lan, Y., Chen, X., Xu, Y., and Ng, E. (1993). Health expectancy of adults in Xichang, China, 1990: autonomy in various activities of daily living. In J-M. Robine, C.D. Mathers, M.R. Bone, and I. Romieu. (eds). Calculation of health expectancies: harmonization, consensus achieved and future perspectives. Paris: John Libbey Eurotext.

Robine, J-M., Colvez. A., Bucquet, D. et al., (1986). L'Espérance de Vie Sans Incapacité en France en 1982. Population, 41,1025-1042.

Robine, J-M., Mathers, C. D., and Bucquet, D. (1993). Distinguishing health expectancies and health-adjusted life expectancies from quality-adjusted life years. American Journal of Public Health, 83(6),797-8.

Rogers, A. (1975). Introduction to multi-regional mathematical demography. New York: John Wiley and Sons.

Rogers, A., Rogers, R.G., and Belanger, A.(1990). Longer life but worse health? Measurement and dynamics. Gerontologist, 30(5), 640-649.

Rogers, A., Rogers, R.G., and Branch, L.G. (1989). Multistate analysis of active life expectancy. Public Health Report, 104(3),222-226.

Roos, N.P., Montgomery, P., and Roos, L.L. (1987). Health care utilization in the years prior to death. Milbank Memorial Fund Quarterly, 65, 231-254.

Saito, Y., Qiao, X., and Jitapunkul, S. (2003).Health expectancy in Asian countries. In J-M., Robine, C. Jagger, C.D. Mathers, E.M. Crimmins, and R.M.Suzman (eds.). Determining health expectancies, Pp289-317. John Wiley and Sons Ltd: England.

Scott, W.K., Macera, C.A., Cornman, C, B., and Sharp, P.A. (1997). Functional health status as a predictor of mortality in men and women over 65. Journal of Clinical Epidemiology, 50, 291-296.

Schoen, R. (1988). Modeling multi-group population. New York: Plenum Press.

Seeman, I. (1992). National Mortality Followback Survey: 1986 summary, United States. Vital Health Statistics, 20 (19). Hyattsville: Maryland.

Steinhauser, K.E., Christakis, N.A., Clipp, E.C., McNeilly, M., McIntyre, L., and Tulsky, J. (2000). Factors considered important at the end of life by patients, family, physicians, and other care providers. Journal of American Medical Association, 284, 2476-2482.

Steinhauser, K.E., Clipp, E.C., McNeilly, M., Christakis, N.A., McIntyre, L.M., and Tulsky, J.A. (2000). In search of a good death: Observations of patients, families, and providers. Annals of Internal Medicine, 132, 825-832.

Thatcher, A. R., Kannisto, V., and Vaupel, J.W. (1998). The force of mortality at ages 80 to 120 . Odense University Press: Odense, Denmark.

Tu, E.J-C., and Chen, K-J. (1994a). Changes in active life expectancy in Taiwan: Compression or expansion? Social Science and Medicine, 39, 1657-1665.

Tu, E.J-C., and Chen, K-J. (1994b). Recentl changes in healthy life expectancy and their implications for medical costs in Taiwan. In C.D. Mathers, J. McCallum, J-M. Robine. (eds.). Advances in health expectancies. Canberra: AGPS, Australian Institute of Health and Welfare. 
United Nations, Population Division (2001). World population prospects: The 2000 revision. New York.

Üstün, T.B., Chatterji, S., Villanueva, M., et al. (2001). WHO multi-country household survey study on health and responsiveness, 2000-2001. GPE discussion paper No. 37. Geneva: World Health Organization. Also available on the worldwide web at www.who.int/evidence.

Wang, M. (1993). Long life is not equal to healthy life. China Economic Press. Beijing.

Wang, Z.L., Zeng, Y., Vaupel, J. W., and Jeune, B. (1998). Age validation of Han Chinese centenarians. Genus, 54 (1-2), 123-141.

Wilkins, R., and Adams, O.B.(1983). Health expectancy in Canada, late 1970s: Demographic, regional, and social dimensions. American Journal of Public Health, 73 (9), 474-519.

Wolf, D.A. and Laditka, S.B. (1997). Stochastic modeling of active life and its expectancy. New York: The Maxwell Center for Demography and Economics of Aging, Syracuse University. Papers in Microsimulation Series Paper No. 4.

Wolinsky, F.D., Callahan, C.M., Fitzgerald, J.F., and Johnson, R.J. (1993). Changes in functional status and the risk of subsequent nursing home placement and death. Journal of Gerontology, 48, S94-S101.

Zeng, Y., and Vaupel, J.W. (2002). Functional capacity and self-evaluation of health and life of the oldest old in China. Journal of Social Issues, 58, No. 4.

Zeng, Y., and Vaupel, J.W. (2003). Mortality trajectory of the oldest old in China. Demographic Research, 8, No.7.

Zeng, Y., Vaupel, J.W., Xiao, Z.Y., Zhang, C.Y., and Liu, Y.Z. (2001). The healthy longevity survey and the active life expectancy of the oldest old in China. Population, 13 (1), 95-116.

Zeng, Y., Vaupel, J.W., Xiao, Z.Y., Zhang, C.Y., and Liu, Y.Z. (2002). Sociodemographic and health profiles of oldest old in China. Population and Development Review, 28, 251-273.

Zhong, Z., Chen, Y., and Yao, K.(1997). Study of a calculation method for healthy life expectancy. Chinese Journal of Population Science, 9(2),75-86. 
Table 1. Biases in estimating status-based disabled and active life expectancies based on the conventional method, as compared to our extended method, which takes into account ADL changes between age $\mathrm{x}$ and death among those who die between ages $\mathrm{x}$ and $\mathrm{x}+1$

\begin{tabular}{|c|c|c|c|c|c|c|}
\hline & \multicolumn{3}{|c|}{ Absolute bias of life expectancy } & \multicolumn{3}{|c|}{ Relative bias (\%) of life expectanc } \\
\hline & Active & Disabled & Total & Active & Disabled & Total \\
\hline \multicolumn{7}{|l|}{ Male } \\
\hline \multicolumn{7}{|l|}{ Over initial Age 80} \\
\hline Active at initial age & 0.077 & $-0.077 * * *$ & 0.000 & 1.36 & $-12.26 * * *$ & 0.00 \\
\hline Disabled at initial age & 0.009 & -0.009 & 0.000 & 0.27 & -0.60 & 0.00 \\
\hline Total & 0.069 & $-0.070^{* * *}$ & 0.000 & 1.29 & $-9.54 * * *$ & 0.00 \\
\hline \multicolumn{7}{|l|}{ Over initial Age 85} \\
\hline Active at initial age & 0.077 & $-0.077 * *$ & 0.000 & 1.89 & $-9.44 * *$ & -0.01 \\
\hline Disabled at initial age & -0.021 & 0.021 & 0.000 & -1.45 & 1.08 & -0.01 \\
\hline Total & 0.062 & $-0.063 * * *$ & 0.000 & 1.69 & $-6.37 * * *$ & -0.01 \\
\hline \multicolumn{7}{|l|}{ Over initial Age 90} \\
\hline Active at initial age & 0.066 & $-0.068 * * *$ & -0.001 & 2.11 & $-8.48 * * *$ & -0.03 \\
\hline Disabled at initial age & $-0.052 *$ & 0.052 & -0.001 & $-6.49 *$ & 2.92 & -0.02 \\
\hline Total & 0.039 & $-0.040 *$ & -0.001 & 1.50 & $-3.96 *$ & -0.03 \\
\hline \multicolumn{7}{|l|}{ Over initial Age 95} \\
\hline Active at initial age & 0.057 & $-0.062 * *$ & -0.005 & 2.22 & $-8.58 * *$ & -0.17 \\
\hline Disabled at initial age & $-0.061 * * *$ & 0.059 & -0.002 & $-11.18 * * *$ & 3.95 & -0.10 \\
\hline Total & 0.016 & -0.021 & -0.004 & 0.88 & -2.10 & -0.15 \\
\hline \multicolumn{7}{|l|}{ Over initial Age 100} \\
\hline Active at initial age & 0.030 & $-0.062 * *$ & -0.032 & 1.44 & $-10.29 *$ & -1.18 \\
\hline Disabled at initial age & $-0.066^{* * *}$ & 0.055 & -0.011 & $-15.35^{* * *}$ & 4.52 & -0.68 \\
\hline Total & -0.019 & -0.002 & -0.021 & -1.52 & -0.25 & -0.98 \\
\hline
\end{tabular}

\section{Female}

Over initial Age 80

Active at initial age

Disabled at initial age

Total

0.083

0.037
0.077

$-0.083 * * *$

$-0.001$

1.28

0.99

$-6.80 * * *$

$-1.34$

$-0.01$

Over initial Age 85

Active at initial age

Disabled at initial age

0.071

$-0.038$

$-0.001$

1.26

$-5.49 * * *$

$-0.01$

Total

0.002

$-0.072 * * *$

$-0.001$

1.63

$-5.76 * * *$

$-0.02$

Over initial Age 90

Active at initial age

0.056

$-0.003$

$-0.001$

0.11

$-0.12$

$-0.02$

1.45

$-3.71 *$

$-0.02$

Disabled at initial age

Total

0.069

$-0.071 * * *$

$-0.002$

2.18

$-0.002$

$-6.26 * * *$

$-0.05$

Over initial Age 95

0.035

$-0.002$

$1.12-0.05$

$-2.44-0.05$

Active at initial age

Disabled at initial age

Total

$0.064-0.072 * *$

$-0.008$

$-0.005$

$-0.007$

2.66

$-4.40 *$

$-6.84 * *$

$-0.23$

Over initial Age 100

$0.026-0.032$

1.48

1.36

$-0.18$

Active at initial age

Disabled at initial age

$0.047-0.088^{* *}$

$-0.041$

$-0.023$

2.48

$-2.29$

$-0.21$

Total

$-0.010$

$-0.019$

$-0.030$

$-10.56^{* * *}$

$-9.21 * *$

$-1.43$

Notes:

(1) absolute bias $=$ results based on conventional method - results based on our extended method.

(2) relative bias $=$ 
results based on conventional method - results based on our extended method

\section{results based on our extended method}

(3) Significant levels of the statistical tests of the bias: * $\mathrm{p}<0.05$; **, $\mathrm{p}<0.01$; ***, $\mathrm{p}<0.001$.

Table 2. Status-based active and disabled life expectancies of Chinese oldest old aged 80-105

\begin{tabular}{|c|c|c|c|c|c|c|}
\hline & \multicolumn{3}{|c|}{ Life Expectancy } & \multicolumn{3}{|c|}{ \% of Life Expectancy } \\
\hline & Active & Disabled & Total & Active & Disabled & Total \\
\hline \multicolumn{7}{|l|}{ Male } \\
\hline \multicolumn{7}{|l|}{ Over initial Age 80} \\
\hline Active at initial age & 5.64 & 0.63 & 6.27 & 89.96 & 10.04 & 100.00 \\
\hline Disabled at initial age & 3.37 & 1.55 & 4.91 & 68.54 & 31.46 & 100.00 \\
\hline Total & 5.39 & 0.73 & 6.12 & 88.06 & 11.94 & 100.00 \\
\hline \multicolumn{7}{|l|}{ Over initial Age 85} \\
\hline Active at initial age & 4.06 & 0.82 & 4.88 & 83.24 & 16.76 & 100.00 \\
\hline Disabled at initial age & 1.45 & 1.93 & 3.39 & 42.87 & 57.13 & 100.00 \\
\hline Total & 3.68 & 0.98 & 4.66 & 78.89 & 21.11 & 100.00 \\
\hline \multicolumn{7}{|l|}{ Over initial Age 90} \\
\hline Active at initial age & 3.15 & 0.80 & 3.94 & 79.77 & 20.23 & 100.00 \\
\hline Disabled at initial age & 0.81 & 1.77 & 2.58 & 31.27 & 68.73 & 100.00 \\
\hline Total & 2.61 & 1.02 & 3.63 & 71.92 & 28.08 & 100.00 \\
\hline \multicolumn{7}{|l|}{ Over initial Age 95} \\
\hline Active at initial age & 2.55 & 0.72 & 3.27 & 77.90 & 22.10 & 100.00 \\
\hline Disabled at initial age & 0.55 & 1.50 & 2.05 & 26.75 & 73.25 & 100.00 \\
\hline Total & 1.87 & 0.99 & 2.85 & 65.41 & 34.59 & 100.00 \\
\hline \multicolumn{7}{|l|}{ Over initial Age 100} \\
\hline Active at initial age & 2.09 & 0.60 & 2.70 & 77.69 & 22.31 & 100.00 \\
\hline Disabled at initial age & 0.43 & 1.21 & 1.64 & 26.17 & 73.83 & 100.00 \\
\hline Total & 1.24 & 0.91 & 2.16 & 57.66 & 42.34 & 100.00 \\
\hline \multicolumn{7}{|l|}{ Female } \\
\hline \multicolumn{7}{|l|}{ Over initial Age 80} \\
\hline Active at initial age & 6.44 & 1.22 & 7.66 & 84.03 & 15.97 & 100.00 \\
\hline Disabled at initial age & 3.77 & 2.81 & 6.59 & 57.31 & 42.69 & 100.00 \\
\hline Total & 6.11 & 1.41 & 7.53 & 81.21 & 18.79 & 100.00 \\
\hline \multicolumn{7}{|l|}{ Over initial Age 85} \\
\hline Active at initial age & 4.35 & 1.25 & 5.59 & 77.71 & 22.29 & 100.00 \\
\hline Disabled at initial age & 2.09 & 2.54 & 4.63 & 45.18 & 54.82 & 100.00 \\
\hline Total & 3.85 & 1.53 & 5.38 & 71.57 & 28.43 & 100.00 \\
\hline \multicolumn{7}{|l|}{ Over initial Age 90} \\
\hline Active at initial age & 3.15 & 1.13 & 4.29 & 73.55 & 26.45 & 100.00 \\
\hline Disabled at initial age & 1.13 & 2.25 & 3.38 & 33.52 & 66.48 & 100.00 \\
\hline Total & 2.44 & 1.52 & 3.97 & 61.58 & 38.42 & 100.00 \\
\hline \multicolumn{7}{|l|}{ Over initial Age 95} \\
\hline Active at initial age & 2.42 & 1.06 & 3.47 & 69.60 & 30.40 & 100.00 \\
\hline Disabled at initial age & 0.71 & 1.95 & 2.66 & 26.73 & 73.27 & 100.00 \\
\hline Total & 1.73 & 1.42 & 3.14 & 54.96 & 45.04 & 100.00 \\
\hline \multicolumn{7}{|l|}{ Over initial Age 100} \\
\hline Active at initial age & 1.91 & 0.96 & 2.86 & 66.55 & 33.45 & 100.00 \\
\hline Disabled at initial age & 0.42 & 1.73 & 2.15 & 19.41 & 80.59 & 100.00 \\
\hline Total & 0.97 & 1.45 & 2.41 & 40.07 & 59.93 & 100.00 \\
\hline
\end{tabular}


Table 3. Status-based life table proportions of the extent of morbidity before dying

\begin{tabular}{|c|c|c|c|c|c|}
\hline & $\begin{array}{c}\text { Slight } \\
\text { morbidity }\end{array}$ & $\begin{array}{l}\text { Moderate } \\
\text { morbidity }\end{array}$ & $\begin{array}{c}\text { Severe } \\
\text { morbidity }\end{array}$ & $\begin{array}{l}\text { Long-term } \\
\text { severe } \\
\text { morbidity }\end{array}$ & Total \\
\hline \multicolumn{6}{|l|}{ Male } \\
\hline \multicolumn{6}{|l|}{ Over initial Age 80} \\
\hline Active at initial age & 40.72 & 20.60 & 23.55 & 15.13 & 100.00 \\
\hline Disabled at initial age & 34.12 & 23.22 & 22.34 & 20.32 & 100.00 \\
\hline Total & 39.99 & 20.89 & 23.42 & 15.70 & 100.00 \\
\hline \multicolumn{6}{|l|}{ Over initial Age 85} \\
\hline Active at initial age & 32.30 & 24.72 & 24.12 & 18.86 & 100.00 \\
\hline Disabled at initial age & 24.14 & 23.37 & 24.87 & 27.61 & 100.00 \\
\hline Total & 31.09 & 24.52 & 24.23 & 20.16 & 100.00 \\
\hline \multicolumn{6}{|l|}{ Over initial Age 90} \\
\hline Active at initial age & 32.20 & 28.38 & 23.78 & 15.64 & 100.00 \\
\hline Disabled at initial age & 29.56 & 26.27 & 23.79 & 20.37 & 100.00 \\
\hline Total & 31.59 & 27.90 & 23.78 & 16.72 & 100.00 \\
\hline \multicolumn{6}{|l|}{ Over initial Age 95} \\
\hline Active at initial age & 32.73 & 27.58 & 22.80 & 16.89 & 100.00 \\
\hline Disabled at initial age & 28.51 & 27.34 & 24.47 & 19.68 & 100.00 \\
\hline Total & 31.29 & 27.50 & 23.37 & 17.84 & 100.00 \\
\hline \multicolumn{6}{|l|}{ Over initial Age 100} \\
\hline Active at initial age & 31.26 & 31.08 & 23.16 & 14.50 & 100.00 \\
\hline Disabled at initial age & 24.81 & 29.56 & 26.81 & 18.82 & 100.00 \\
\hline Total & 27.89 & 30.29 & 25.06 & 16.76 & 100.00 \\
\hline \multicolumn{6}{|l|}{ Female } \\
\hline \multicolumn{6}{|l|}{ Over initial Age 80} \\
\hline Active at initial age & 26.65 & 23.98 & 25.84 & 23.53 & 100.00 \\
\hline Disabled at initial age & 21.59 & 27.28 & 22.37 & 28.76 & 100.00 \\
\hline Total & 26.04 & 24.38 & 25.42 & 24.16 & 100.00 \\
\hline \multicolumn{6}{|l|}{ Over initial Age 85} \\
\hline Active at initial age & 25.23 & 25.25 & 27.11 & 22.41 & 100.00 \\
\hline Disabled at initial age & 21.30 & 22.55 & 26.71 & 29.43 & 100.00 \\
\hline Total & 24.37 & 24.66 & 27.02 & 23.95 & 100.00 \\
\hline \multicolumn{6}{|l|}{ Over initial Age 90} \\
\hline Active at initial age & 26.37 & 23.33 & 28.39 & 21.91 & 100.00 \\
\hline Disabled at initial age & 21.35 & 21.52 & 27.78 & 29.36 & 100.00 \\
\hline Total & 24.60 & 22.69 & 28.17 & 24.53 & 100.00 \\
\hline \multicolumn{6}{|l|}{ Over initial Age 95} \\
\hline Active at initial age & 22.49 & 26.74 & 25.96 & 24.81 & 100.00 \\
\hline Disabled at initial age & 17.47 & 25.79 & 26.53 & 30.21 & 100.00 \\
\hline Total & 20.46 & 26.36 & 26.19 & 27.00 & 100.00 \\
\hline \multicolumn{6}{|l|}{ Over initial Age 100} \\
\hline Active at initial age & 21.55 & 27.16 & 25.97 & 25.33 & 100.00 \\
\hline Disabled at initial age & 14.24 & 28.33 & 25.57 & 31.87 & 100.00 \\
\hline Total & 16.87 & 27.91 & 25.71 & 29.51 & 100.00 \\
\hline
\end{tabular}


Figure 1. Percentage distribution of the underestimation of disabled life expectancies based on the conventional method, which assumes no functional status changes between age $\mathrm{x}$ and death among those who die between age $\mathrm{x}$ and $\mathrm{x}+1$

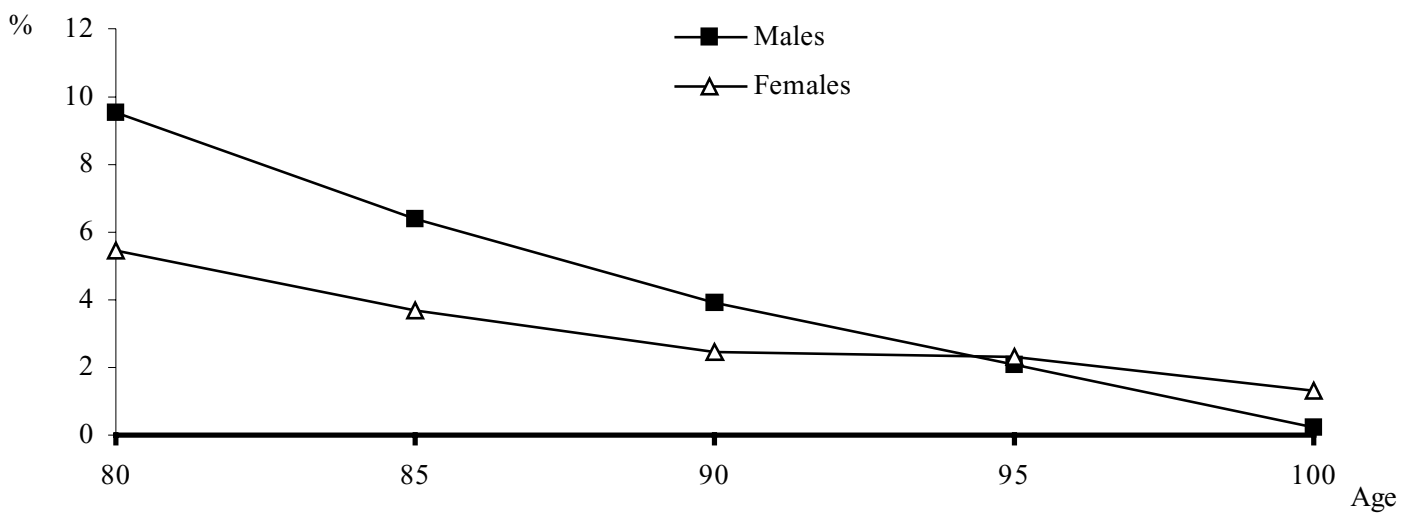


Figure 2a Observed and Fitted Single-Year Age-Specific Central Death Rates Active Males

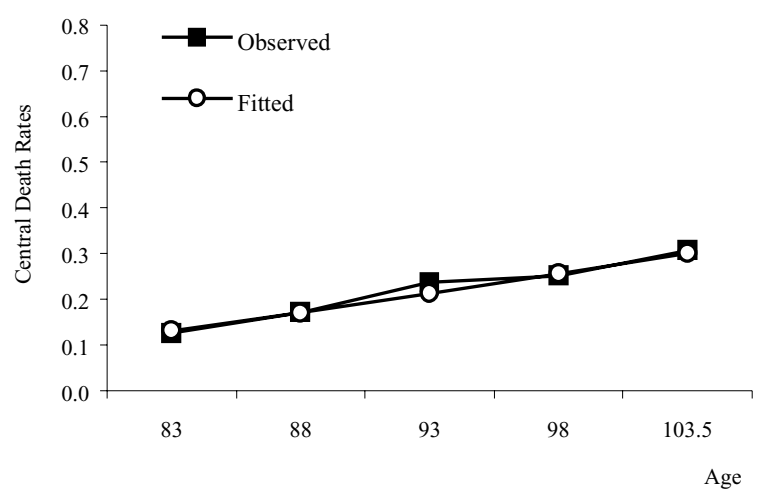

Figure 2c Observed and Fitted Single-Year Age-Specific Central Death Rates

\section{Active Females}

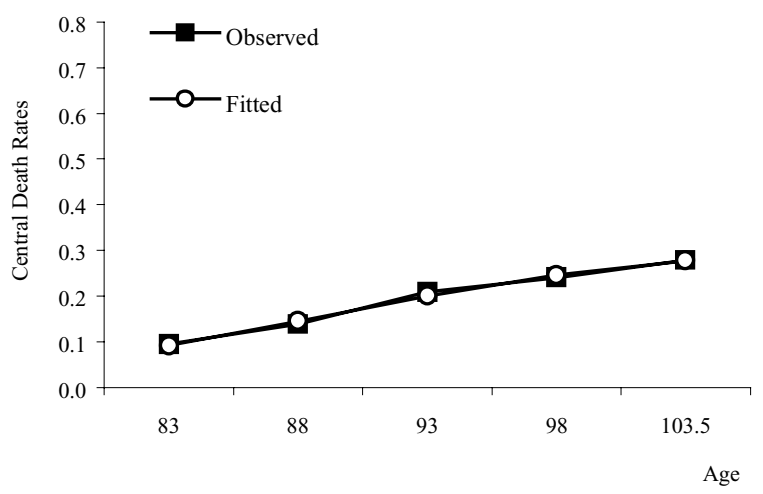

Figure 2b Observed and Fitted Single-Year Age-Specific Central Death Rates

\section{Disabled Males}

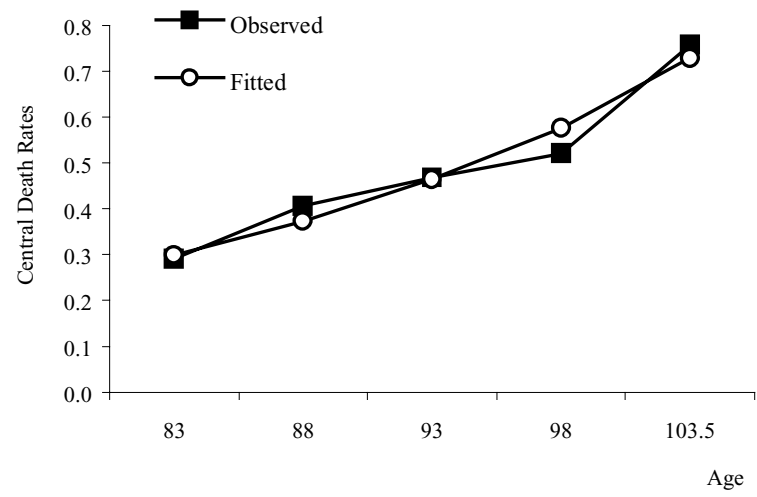

Figure 2d Observed and Fitted Single-Year Age-Specific Central Death Rates Disabled Females

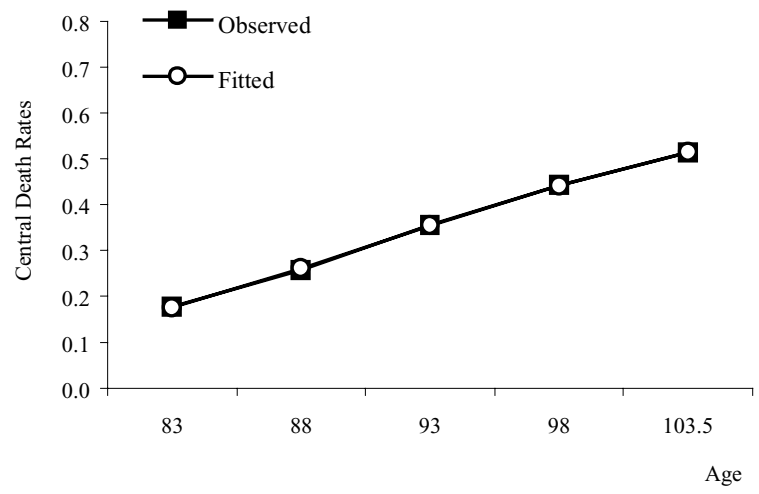

Note: Fitted curves in Figures 1a-1d are based on logistics model: $\mu_{i}(x)=c_{i}+\frac{a_{i} e^{b_{i} x}}{1+d_{i} e^{\left(b_{i} x-1\right)}}$ 
Figure 3a Observed and Fitted Two-Year Age-specific Probabilities of Remaining Active Status 2p 11 (x) Males.

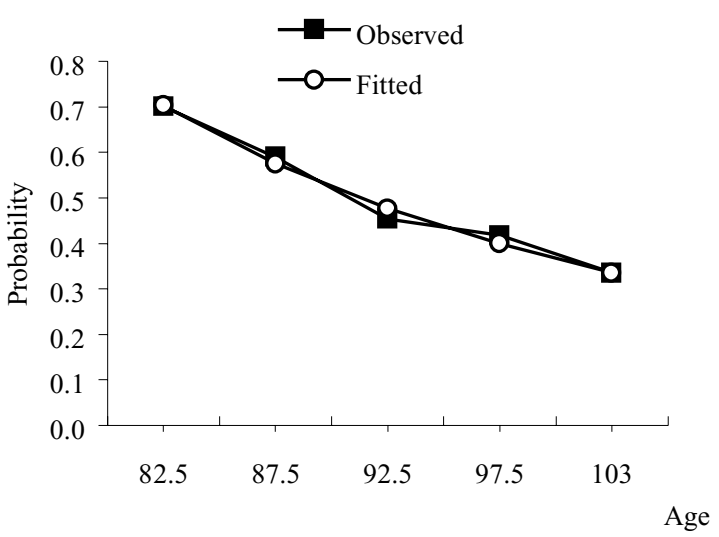

Figure 3c Observed and Fitted Two-Year Age-specific Probabilities of Remaining Active Status 2p 11 (x) Females

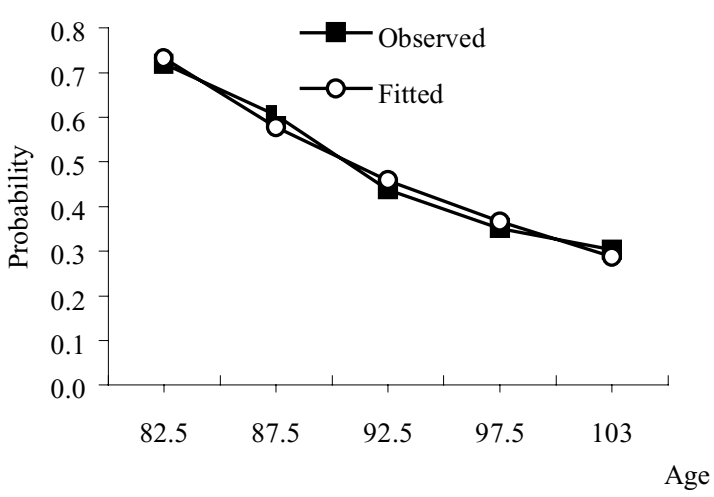

Figure 3b Observed and Fitted Two-Year Age-specific Probabilities of Transition from Disable to Active 2p 21 (x) Males

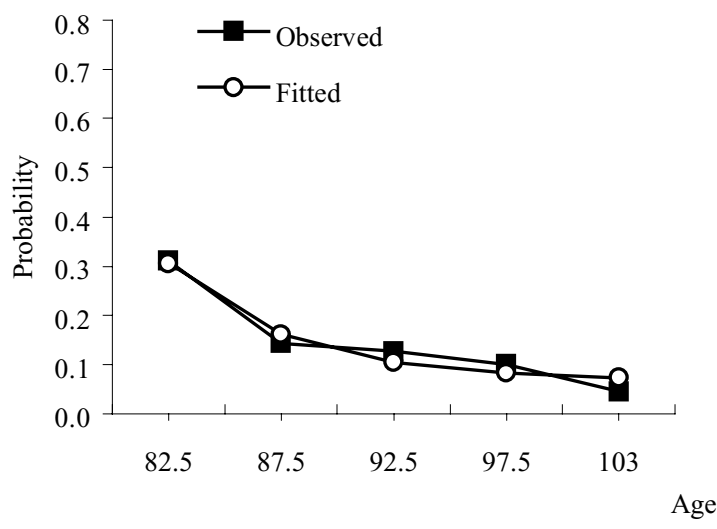

Figure 3d Observed and Fitted Two-Year Agespecific Probabilities of Transition from Disable to Active 2 p21 (x) Eemales

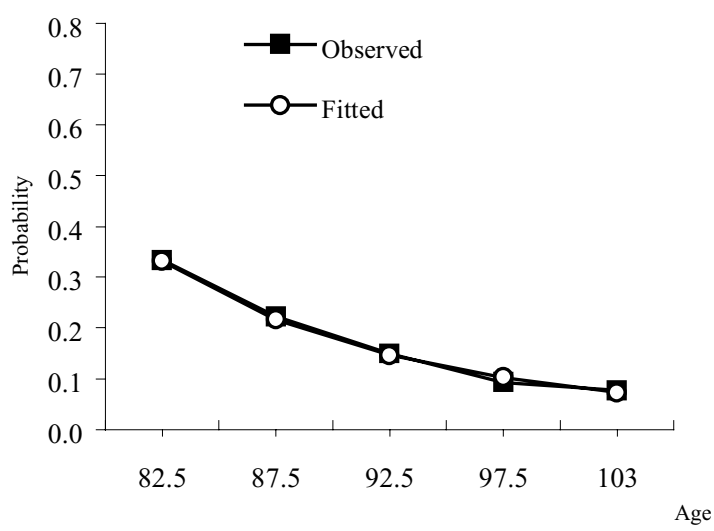

Note: Fitted curves in Figures 2a-2d are based on exponential decline model: ${ }_{2} p_{i 1}(x)=a_{i}+b_{i} e^{-c_{i} x}$ 
Figure 4. Percent of Remaining Life Spent in Active Status among Chinese Oldest Old Males and Females Who Are Active or Disable at Initail Age y

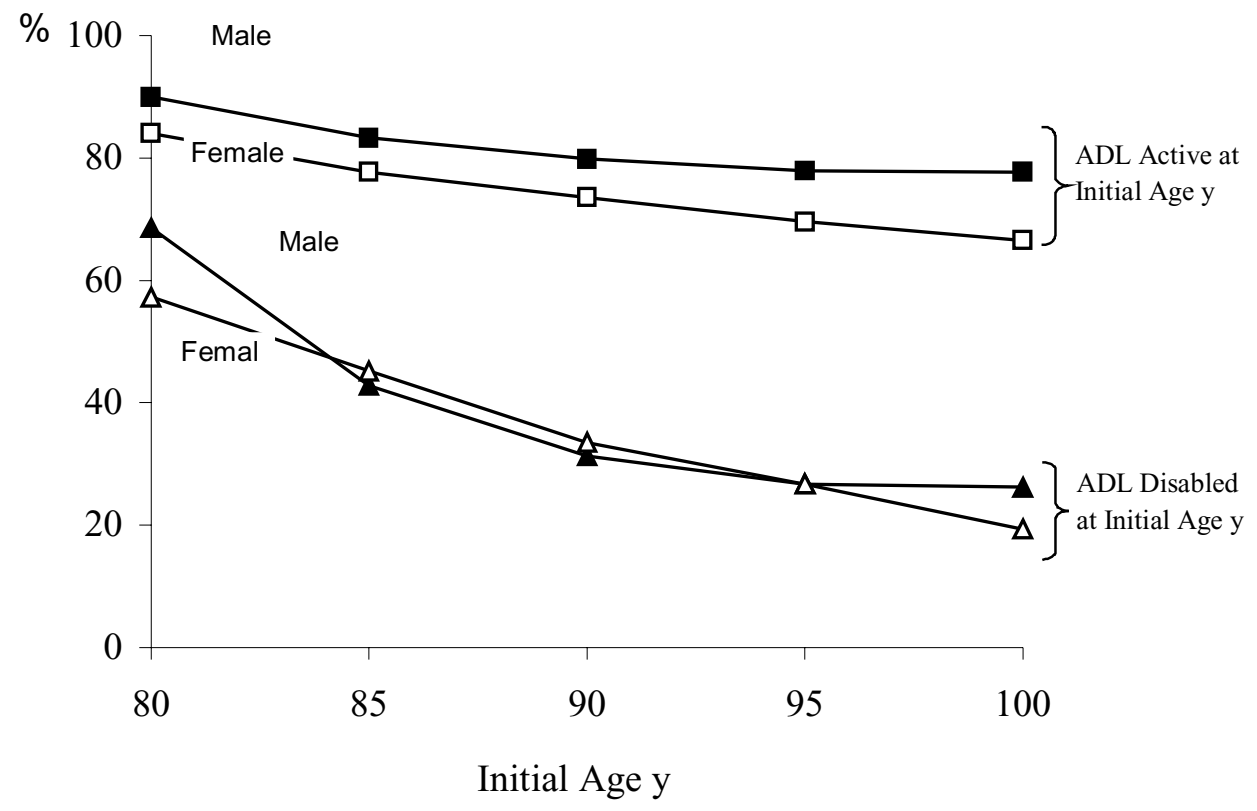


Figure $5 \mathrm{a}$. The life table proportions of slight morbidity before dying by ADL status at initial ages
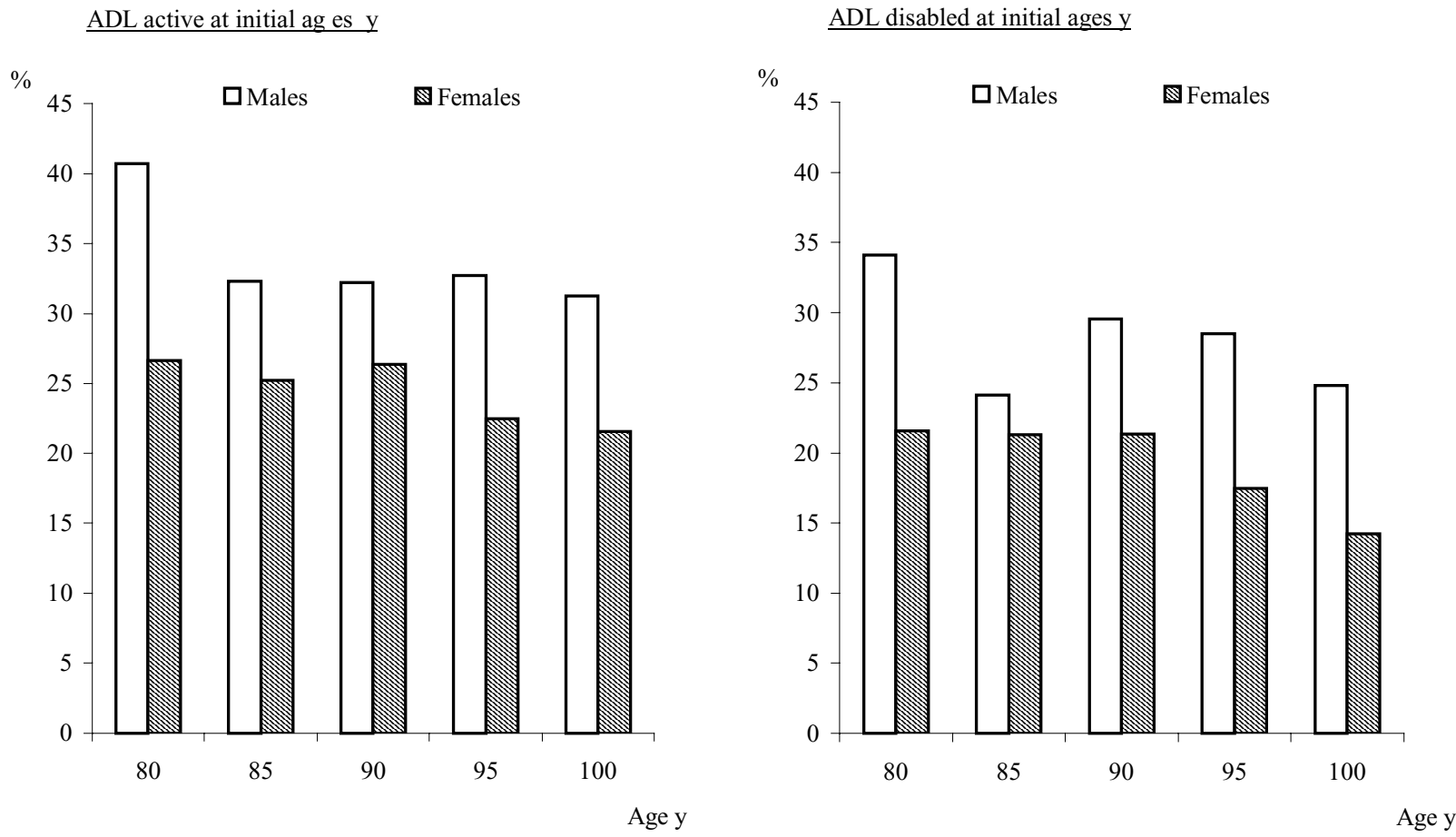

Figure $5 b$. The life table proportions of long-term severe morbidity before dying by ADL status at initial ages
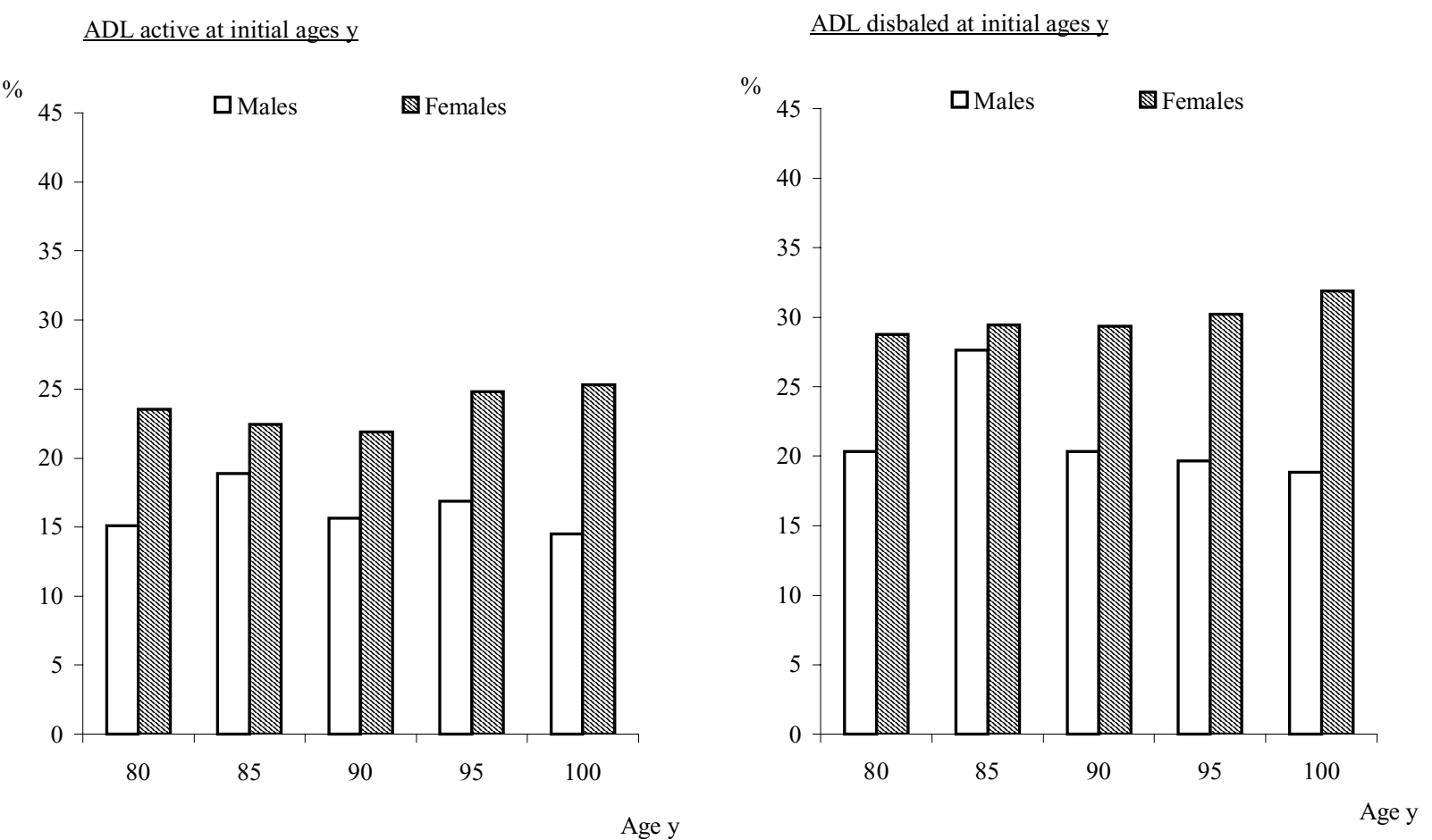